\title{
Kapitel 5 \\ Die Inhalts-Seite narrativer Vertextungen bei Paulus
}

\section{Einleitung}

Ein die minimalistische Definition einer Erzählung nach Köppe und Kindt erfüllender Text handelt von mindestens zwei Ereignissen, die „temporal geordnet“ und „in mindestens einer weiteren sinnhaften Weise miteinander verknüpft sind. “1 Im Folgenden wird der Frage nachgegangen, wie temporale Ordnung und sinnhafte Verknüpfung im Rahmen des hier vorgestellten textgrammatischen Ansatzes erfasst werden können. Dabei wird von der Systematisierung möglicher Propositionsbeziehungen ausgegangen, wie sie in Abb. 12 dargestellt wird. ${ }^{2}$

Die Diskussion folgt der Grobgliederung in chronologische und nichtchronologische Propositionalverbindungen. Im ersten Fall ist der Aspekt der temporalen Ordnung durch den kommunikativen Fokus der Konnexion selbst thematisiert. Dennoch sind die zeitlichen Beziehungen zwischen den in zwei zusammengehörigen Propositionen ausgedrückten Sachverhalten auf sehr unterschiedliche Weise temporal aufeinander bezogen. Es wird also genau nachzuzeichnen sein, von welchen temporalen Relationen Paulus als Erzählender Gebrauch machte. Weniger offensichtlich ist bei den chronologischen Konnexionen die Antwort auf die Frage, wie die „sinnhafte Verknüpfung“ der Geschehnisse gewährleistet werden könnte.

Im Fall der nicht-chronologischen Konnexionen ist die Situation genau umgekehrt: In den meisten Fällen bringen diese Konnexion exakt diese „sinnhafte“ Verbindung zwischen zwei Sachverhalten selbst zum Ausdruck. Hier wird also insbesondere zu klären sein, wie einerseits das Spektrum der inhaltlichen Relationen aussieht und wie Paulus davon Gebrauch macht - und andererseits, wie der Aspekt der temporalen Ordnung im Text kommuniziert werden kann.

1 Köppe und Kindt, Erzähltheorie, 43.

2 Abb. 12 aus GGNT 352b. 


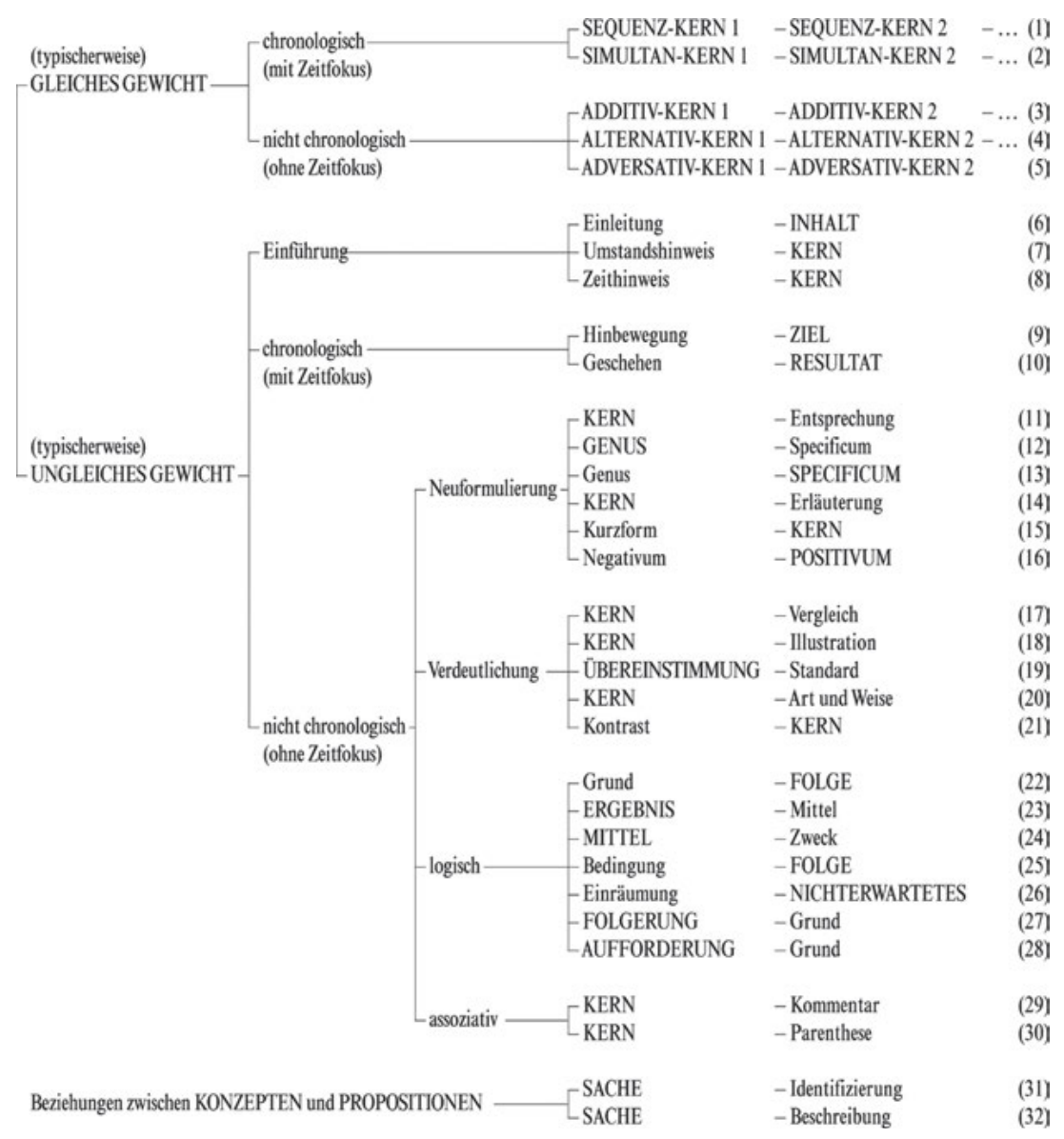

Abb. 12: Übersicht über mögliche Beziehungen zwischen Propositionen eines Textes nach Heinrich von Siebenthal.

\section{Temporale Ordnung bei temporalen Konnexionen}

\section{1 Übersicht}

Der Aspekt der zeitlichen Anordnung kommt am deutlichsten in Konnexionen zum Ausdruck, die einen zeitbezogenen Fokus haben. ${ }^{3}$ Dabei kann entweder der

3 Vgl. GGNT 327-330. Die gesonderte Behandlung temporaler Konnexionen lässt sich daraus sehr stark begründen, dass die entsprechenden Konnektoren „als Argumente notwendig 
Fall vorliegen, dass (a) gleichgewichtige Kerne nebeneinander treten oder (b) die eine Proposition lediglich einen Zeithinweis zum betonten Kern liefert. ${ }^{4}$

Diese beiden Möglichkeiten der kommunikativen Gewichtung gelten für sämtliche temporalen Konnexionen, wobei das Gemeinte auf der grammatischen Textstrukturseite durch spezifische Konnektoren markiert sein kann. Neben der (I) kommunikativen Gewichtung der einzelnen Propositionen spielt natürlich auch (II) die exakte zeitliche Relation der gemeinten Sachverhalte eine Rolle: Temporale Konnexionen können (a) entweder Abfolge oder (b) Gleichzeitigkeit zum Ausdruck bringen. Abb. 13 gibt einen Überblick über die resultierenden temporalen Konnexionen.

\begin{tabular}{|l|l|l|l|}
\cline { 3 - 4 } \multicolumn{2}{c|}{} & \multicolumn{2}{c|}{ TEMPORALE BEZIEHUNG } \\
\cline { 2 - 4 } \multicolumn{2}{c|}{} & Abfolge & Gleichzeitigkeit \\
\hline $\begin{array}{l}\text { KOMMUNIKATIVE } \\
\text { GEWICHTUNG }\end{array}$ & gleich & $\begin{array}{l}\text { SEQUENZ-KERN 1- } \\
\text { SEQUENZ-KERN 2 }\end{array}$ & $\begin{array}{l}\text { SIMULTAN-KERN 1- } \\
\text { SIMULTAN-KERN 2 }\end{array}$ \\
\cline { 2 - 4 } & unterschiedlich & Zeithinweis-KERN & Zeithinweis-KERN \\
\hline
\end{tabular}

Abb. 13: Temporale Konnexions-Subtypen.

In allen Fällen sind weitere Differenzierungen möglich, die zum Verständnis der im Propositionalgefüge ausgedrückten temporalen Beziehungen von Bedeutung sind. So lassen sich beispielsweise temporale Konnexionen, die ein „Aufeinanderfolgen“5 zum Ausdruck bringen, grundsätzlich in „,vor- und nachzeitige“ Konnexionen unterteilen. ${ }^{6}$

temporal spezifizierte Ereignisaussagen“ aufweisen, wodurch sie sich deutlich von den aussagenlogisch fundierten Sachverhaltsrelationen unterscheiden. Vgl. Breindl, „Semantische Klassifikation,“ 255.

4 GGNT 327.

5 So Duden 1763.

6 Die Rede von Nachzeitigkeit darf hier nicht verwechselt werden mit dem „nachzeitigen (bzw. späteren) Narrationstyp“ von Genette (siehe unten, Kapitel 6, Abschnitt 3.2.3). Unter der letztgenannten Kategorie geht es um das zeitliche Verhältnis des Erzählten zum Erzählenden. Im Hinblick auf Konnexionen wird demgegenüber das Verhältnis zweier Ereignisse innerhalb der erzählten Welt besprochen. Dasselbe gilt für den gleichzeitigen Narrationstyp und gleichzeitige Konnexionen. Mit „nachzeitiger/gleichzeitiger Narration“ kann theoretisch beides gemeint sein. 
$\mathrm{Zu}$ beachten ist, dass im HDK 2 eine grundsätzlich andere Untergliederung der temporalen Klasse an Konnektoren gewählt wird: es wird dabei das Verhältnis vom „Referenzsachverhalt“ gegenüber dem „situierten Sachverhalt“ betrachtet, mit anderen Worten „ob der Temporalkonnektor den Zeitpunkt ..., die Dauer ..., oder die Häufigkeit eines Ereignisses ... bestimmt. “7 Diese Orientierung an Zeitpunkt-/Dauer bzw. Frequenz wird in der vorliegenden Arbeit teilweise für die Feingliederung der genannten Kategorien verwendet.

\subsection{Vorzeitige Konnexionen}

Von einer vorzeitigen temporalen Konnexion spricht man, wenn bei zwei aufeinanderfolgenden Propositionen die erste das frühere Ereignis beinhaltet. Vorausgesetzt ist dabei (1) eine „feste Textfolge,“8 also der Fall, dass die Abfolge der beiden Propositionen nur in dieser Reihenfolge erfolgen kann. Der Konnektor leitet dabei die zweite (vom späteren Ereignis sprechende) Proposition ein. Textfolgefest sind vor allem koordinierende Konjunktionen und Adverbien. Die Linearisierung im Text ist bei dieser Umsetzung des Konnexions-Subtyps ikonisch, bildet also die Chronologie der Sachverhalte in der erzählten Welt ab.

Namensgebend ist also, dass im Standardfall der adverbialen Aneinanderreihung von Propositionen („X geschah. Dann geschah Y.“) in der ersten Proposition - die nicht durch einen Konnektor markiert ist - ein Geschehen zum Ausdruck kommt, welches gegenüber dem Geschehen der zweiten Proposition vorzeitig ist. In Gal 1,17-18 folgen vorzeitige Konnexionen mit koordinierender Konjunktion und Adverb direkt aufeinander, wie Abb. 14 zeigt.

Bei (2) „textfolgefreier“ Verknüpfung ist die Perspektive genau umgekehrt: ${ }^{9}$ Bei der vorzeitigen Konnexion steht der Konnektor (v. a. subordinierende Konjunktionen und Präpositionen) ${ }^{10}$ in diesem Fall in derjenigen Proposition, welche das frühere Ereignis selbst beinhaltet. Die Reihenfolge kann nun sowohl ikonisch als auch anti-ikonisch sein. So könnte man die obigen Beispiele im Deutschen wie folgt umformulieren.

Nachdem ich nach Arabien hinabgegangen war, kehrte ich wieder nach Damaskus zurück. Ich kehrte wieder nach Damaskus zurück, nachdem ich nach Arabien hinabgegangen war.

7 Breindl, „Semantische Klassifikation,“ 255.

8 Vgl. hier Duden 1752.

9 Vgl. Duden 1764.

10 Vgl. Duden 1752. 
Nachdem ich wieder nach Damaskus zurückgekehrt war, ging ich nach Jerusalem hinauf. Ich ging nach Jerusalem hinauf, nachdem ich wieder nach Damaskus zurückgekehrt war.

\begin{tabular}{|c|c|c|}
\hline $\begin{array}{l}\text { Konnektor: } \\
\text { koordinierende Konjunktion }\end{array}$ & 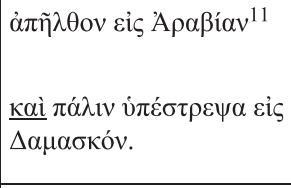 & $\begin{array}{l}\text { Ich ging nach Arabien hinab } \\
\frac{\text { und (dann) }}{\text { kehrte ich wieder }} \\
\text { nach Damaskus zurück. }\end{array}$ \\
\hline $\begin{array}{l}\text { Konnektor: } \\
\text { Adverb }\end{array}$ & 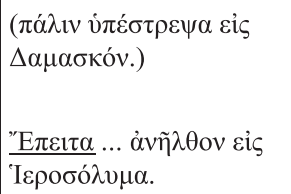 & $\begin{array}{l}\text { (Ich kehrte wieder nach } \\
\text { Damaskus zurück.) } \\
\text { Danach ... ging ich hinauf } \\
\text { nach Jerusalem. }\end{array}$ \\
\hline
\end{tabular}

Abb. 14: Vorzeitige Konnexionen mit ikonischer Textfolge.

Die Tatsache, dass der Konnektor nun in den jeweils anderen Teil der Konnexion integriert ist oder der Umstand, dass die Nennung im Text in anderer Abfolge geschehen kann, bedeuten also nicht, dass eine andere Art des „zeitlichen Aufeinanderfolgens"12 vorliegen würde.

Semantisch-kommunikativ betrachtet ist der Unterschied vielmehr vor allem derjenige der oben angesprochenen Gewichtung: ${ }^{13}$ Steht (1) der Konnektor in der Proposition, welche auf das vorzeitige Geschehen folgt - es handelt sich dann in der Regel um ein Adverb - dann liegt meist eine Reihung gleichwertiger SEQUENZ-Kerne vor. Ansonsten (2) hat das durch den Konnektor markierte vorzeitige Geschehen meist lediglich die stützende Funktion innerhalb eines Zeithinweis-KERN-Gefüges. ${ }^{14}$

11 Innerhalb von Gal 1,17 sind diese beiden Propositionen wiederum der positive Anteil eines Negativum-POSITIVUM-Gefüges. Siehe unten, Abschnitt 3.6 und dann Abschnitt 5.

12 Duden 1763.

13 Das Deutsche weist gegenüber dem Griechischen hier häufig weitere Nuancierungen auf, die nicht selten mit der im Deutschen durch die Tempora ausdrückbaren Zeitenfolge zusammenhängen. Vgl. etwa Duden 1766 zum „nachdem“-Satz.

14 Die starke Abhängigkeit dieser Regel von der konkreten kommunikativen Situation zeigt sich bereits am oben umformulierten Beispiel: „Ich kehrte wieder nach Damaskus zurück, nachdem ich nach Arabien hinabgegangen war.“ Als Antwort auf die Frage mit betontem „,bevor“ (,Kehrtest Du nach Damaskus zurück, bevor Du nach Arabien hinabgingst?“) läge das kommunikative Gewicht eindeutig auf dem Temporalsatz bzw. auf dem Konnektor selbst. 


\subsection{Nachzeitige Konnexionen}

Analog zum bisher Gesagten spricht man von einem nachzeitigen Verhältnis, wenn bei fester Textfolge „die zweite Aussage einen Sachverhalt [versprachlicht], der temporal vor dem Sachverhalt der ersten Aussage angesiedelt ist. " ${ }^{15}$ Im Text erscheint dann (d.h. im Fall einer Verknüpfung durch ein Adverb) folglich das namensgebende (gegenüber dem in der erzählten Welt zuerst geschehenden Ereignis) nachzeitige Geschehen zuerst, wie dies auch Abb. 15 illustriert. Die Linearisierung im Text ist also anti-ikonisch gegenüber der Reihenfolge der tatsächlichen Situationen.

\begin{tabular}{|c|c|c|}
\hline Konnektor: Adverb & 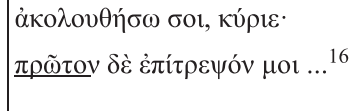 & $\begin{array}{l}\text { Ich will Dir nachfolgen, } \\
\text { Herr. } \\
\underline{\text { Zunächst erlaube mir aber ... }}\end{array}$ \\
\hline
\end{tabular}

Abb. 15: Nachzeitige Konnexion mit anti-ikonischer Textfolge.

Alternativ kann auch hier die Perspektive umgekehrt werden: Der Konnektor (dann eine subordinierende Konjunktion oder eine Präposition) kann auch in das nachzeitige Geschehen selbst integriert werden, wobei dann diese Proposition in der Regel lediglich einen Zeithinweis liefert und die Anordnung frei ist, also ikonisch oder anti-ikonisch vorliegen kann. Also z. B.:

Erlaube mir ..., bevor ich Dir nachfolge.

Bevor ich Dir nachfolge, erlaube mir ...

Nachzeitige Zeithinweise weisen eine Besonderheit auf: Sie können in zwei große Klassen unterteilt werden, je nachdem, ob sie dafür sorgen, dass im KERN der Fokus auf einen vorausgehenden Zeitpunkt oder eine vorausgehende Zeitdauer gelegt wird. ${ }^{17}$

Das Deutsche differenziert hier durch „,vor/bevor/ehe“ für die Markierung eines Zeitpunkts im Kern und „bis (dass/dahin), bislang“ für die Fokussierung auf eine Zeitdauer in der (meist) betonten Proposition. So ist die Formulierung des Kerns in den folgenden beiden Beispielen in Abb. 16 zwar identisch, die Handlung ist aber aufgrund des unterschiedlich eingeleiteten Zeithinweises zu diesem Kern sehr unterschiedlich dargestellt:

15 Duden 1767.

16 Lk 9,61. Das Beispiel wird bei GGNT 329b angeführt. Der paulinische Gebrauch (siehe unten, Kapitel 7, Abschnitt 3.2.1) bietet keine gute Illustration.

17 Vgl. Duden 1767. 


\begin{tabular}{|l|l|}
\hline Fokus auf Zeitpunkt & Fokus auf Zeitdauer \\
\hline $\begin{array}{l}\text { Er rauchte, [KERN] } \\
\text { bevor seine Mutter anrief. [Zeithinweis] }\end{array}$ & $\begin{array}{l}\text { Er rauchte, [KERN] } \\
\text { bis seine Mutter anrief. [Zeithinweis] }\end{array}$ \\
\hline
\end{tabular}

Abb. 16: Nachzeitige Konnexionen mit ikonischer Textfolge und unterschiedlichem Fokus im KERN.

Eine ganz analoge Differenzierung innerhalb der temporalen, nachzeitigen, nicht-gleichwertigen Konnexionen aufgrund des verwendeten Konnektors ist auch im Griechischen möglich. Hier zeigt sich bereits die Vielfältigkeit, mit welcher „temporale Ordnung“innerhalb eines Textes hergestellt werden kann.

\subsection{Gleichzeitige Konnexionen}

Ebenso vielfältig sind die Differenzierungsmöglichkeiten innerhalb der neben der Abfolge zweiten großen Unterkategorie temporaler Ordnung, der Gleichzeitigkeit:

Prototypisch liegt hierbei schlicht (1) ein Fokus auf dem sich im Verlauf befindlichen Nebeneinanderlaufen zweier Sachverhalte vor. Ein Ereignis, Ereignisbündel oder Zustand (ausgedrückt durch Proposition 1) gilt „während“ (subordinierende Konjunktion) sich etwas anderes ereignet bzw. „während“ (Präposition) eines anderen Sachverhaltes (Proposition 2). Auch hier ist ein adverbialer Konnektor möglich, der dann in Proposition 2 integriert ist. Was die zeitliche Ausdehnung betrifft, ist das in Proposition 2 Gemeinte meist ein kürzeres Geschehen. Vergleiche hierzu die Variation der folgenden Propositionalstruktur aus 1. Thess 3,4, wie sie in Abb. 17 dargestellt ist.

Es kann durch den Konnektor (und andere Faktoren, wie etwa das gewählte Tempus) auch markiert werden, dass es sich (2) bei der gemeinten Gleichzeitigkeit wie im Beispiel aus Abb. 18 um eine wiederholt eintretende Konstellation handelt. Im Deutschen kann dieser Aspekt etwa durch die subordinierende Konjunktion „sooft“ kommuniziert werden. Aber auch „wenn“ mit Präteritum muss iterativ (im Sinn von „,immer wenn“) aufgefasst werden (,Wenn ihr zusammen kamt ...“). ${ }^{18}$

Neben dem bloßen Festhalten des (einmaligen oder wiederholten) Nebeneinanderlaufens ist es auch möglich, auf (3) den Abschluss der Gleichzeitigkeit $\mathrm{zu}$ fokussieren, was im Deutschen durch die subordinierende Konjunktion

18 Vgl. Duden 1769. Ansonsten wird „als“ verwendet. 


\begin{tabular}{|c|c|c|}
\hline $\begin{array}{l}\text { Subordinierende } \\
\text { Konjunktion }\end{array}$ & 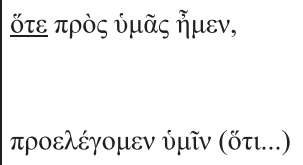 & $\begin{array}{l}\text { Während wir bei euch waren, } \\
\text { sagten wir euch voraus(, dass ...) }\end{array}$ \\
\hline Präposition & & $\begin{array}{l}\text { Während unseres Aufenthaltes } \\
\text { sagten wir euch voraus(, dass ... ) }\end{array}$ \\
\hline Adverb & & $\begin{array}{l}\text { Wir waren bei euch. } \\
\frac{\text { Währenddessen/Damals sagten wir }}{\text { euch voraus(, dass ... })}\end{array}$ \\
\hline
\end{tabular}

Abb. 17: Variation der Konnektoren für gleichzeitige Konnexionen mit Fokus auf den Verlauf.

\begin{tabular}{|c|c|c|}
\hline $\begin{array}{l}\text { Subordinierende } \\
\text { Konjunktion }\end{array}$ & 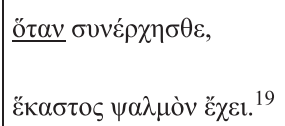 & $\begin{array}{l}\text { Sooft ihr zusammenkommt, } \\
\text { hat jeder ein Lied. }\end{array}$ \\
\hline Präposition & & $\begin{array}{l}\underline{\mathrm{Bei}}^{20} \text { jeder Zusammenkunft } \\
\text { hat jeder ein Lied. }\end{array}$ \\
\hline Adverb & & $\begin{array}{l}\text { Ihr trefft euch regelmäßig. } \\
\text { Jedes Mal/Immer hat jeder } \\
\text { ein Lied. }\end{array}$ \\
\hline
\end{tabular}

Abb. 18: Variation der Konnektoren für gleichzeitige Konnexionen mit Fokus auf Wiederholung.

„solang(e)“ bzw. das Adverb („solange“) geschieht. Ein griechisches Beispiel wird in Abb. 19 geboten.

Das Gegenstück zu dieser Art der gleichzeitigen Konnexion ist dasjenige Paar an Propositionen, welches (4) auf den Beginn des Nebeneinanderlaufens zweier Sachverhalte fokussiert. In Abb. 20 wird diese Konstellation dargestellt.

Als letzte Gruppe gleichzeitiger Konnexionen sind noch diejenigen zu nennen, die auf (5) den Eintritt der Gleichzeitigkeit fokussieren. Im zuvor besprochenen Fall der Konzentration auf den „Beginn,“ welchen man leicht mit diesem Typ

19 1. Kor $14,26$.

20 Der Duden gibt keine Präpositionen für diese Art der Konnexion an. Allerdings ist es durchaus möglich, dass die vom Duden für den bloßen Verlauf gelisteten Präpositionen diese Funktion übernehmen, sofern der abhängige Nominalausdruck durch ein entsprechendes Attribut versehen ist. 


\begin{tabular}{|c|c|c|}
\hline $\begin{array}{l}\text { Subordinierende } \\
\text { Konjunktion }\end{array}$ & 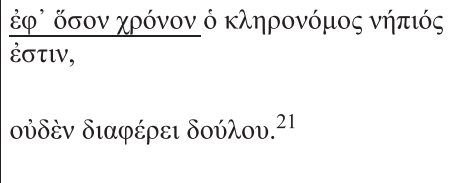 & $\begin{array}{l}\text { Solange der Erbe unmündig } \\
\text { ist, } \\
\text { unterscheidet er sich in } \\
\text { nichts von einem Sklaven. }\end{array}$ \\
\hline Adverb & & $\begin{array}{l}\text { Der Erbe ist unmündig. } \\
\text { Solange unterscheidet er } \\
\text { sich in nichts von einem } \\
\text { Sklaven. }\end{array}$ \\
\hline
\end{tabular}

Abb. 19: Variation der Konnektoren für gleichzeitige Konnexionen mit Fokus auf Abschluss.

\begin{tabular}{|c|c|c|}
\hline Präposition & 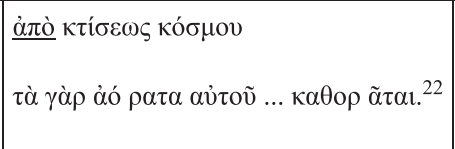 & $\begin{array}{l}\text { Seit Erschaffung der Welt } \\
\text { wird sein unsichtbares } \\
\text { Wesen geschaut. }\end{array}$ \\
\hline $\begin{array}{l}\text { Subordinierende } \\
\text { Konjunktion }\end{array}$ & & $\begin{array}{l}\frac{\text { Seitdem die Welt erschaffen }}{\text { wurde, }} \\
\text { wird sein unsichtbares } \\
\text { Wesen geschaut. }\end{array}$ \\
\hline Adverb & & $\begin{array}{l}\text { Die Welt wurde erschaffen. } \\
\frac{\text { Seitdem }}{23}^{23} \text { wird sein } \\
\text { unsichtbares Wesen } \\
\text { geschaut. }\end{array}$ \\
\hline
\end{tabular}

Abb. 20: Variation der Konnektoren für gleichzeitige Konnexionen mit Fokus auf Beginn.

Konnexionen verwechseln könnte, war stets ein Verlauf im Blick, es wurde also ausgesagt, dass eine Gleichzeitigkeit zweier Sachverhalte seit einem bestimmten Zeitpunkt gelte. Es kann jedoch auch dieser Zeitpunkt selbst in den Fokus gerückt werden, ohne dass das Andauern der Gleichzeitigkeit im Zentrum steht, wie dies etwa in Abb. 21 der Fall ist.

21 Gal 4,1.

22 Vgl. (mit Umstellung) Röm 1,20.

23 Hier zeigt sich ein recht großer Unterschied in der Verwendungsweise der Konnektoren im Vergleich zwischen dem Deutschen und dem Griechischen: Der Duden listet hier „seitdem, seither, inzwischen, derweil, unterdessen.“ GGNT 330a listet hingegen gar keine Adverbien. Eine Durchsicht gängiger deutscher Übersetzungen des NTs bestätigt, dass dort die Wortformen entweder nicht verwendet werden oder aber eine andere Funktion haben („seitdem“ als subordinie-

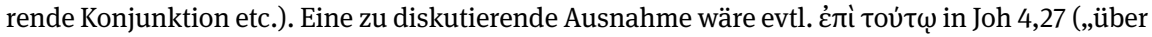




\begin{tabular}{|l|l|}
\hline Fokus auf Verlaufsbeginn & Fokus auf Eintritt \\
\hline Seitdem die Welt erschaffen wurde, & Sobald die Welt erschaffen wurde, \\
wird sein unsichtbares Wesen geschaut. & wurde sein unsichtbares Wesen geschaut. \\
\hline
\end{tabular}

Abb. 21: Variation der Konnektoren für gleichzeitige Konnexionen mit Fokus auf Eintritt.

Auch die Abgrenzung dieser „,sobald“-Gleichzeitigkeit von der („,nachdem“-) Vorzeitigkeit ist nicht immer einfach. (Dies gilt im Beispiel aus Abb. 21 umso mehr, wenn man die Vorvergangenheit „erschaffen worden war“ wählt.) Heinrich von Siebenthal ordnet sämtliche Fälle, in denen der „Sachverhalt ... als abgeschlossen dargestellt wird,“ den temporal-vorzeitigen Konnexionen $\mathrm{zu} .^{24}$ Eine gleichzeitige Konnexion mit Fokus auf dem Eintritt kann folglich nur dann vorliegen, wenn es sich beim den Hintergrund bildenden Geschehen um ein anhaltendes Geschehen handelt. ${ }^{25}$

\section{Sinnhafte Verknüpfung bei nicht-temporalen Konnexionen}

\subsection{Hinführung}

Im Folgenden soll eine Übersicht über die inhaltlichen Beziehungen von Propositionen eines Textes gegeben werden, die nicht (primär) temporal sind. Dieser Fokus auf verschiedene Konnexions-Typen erlaubt eine Explikation der „sinnhaften Verknüpfungen,“ welche Köppe und Kindt für Erzählungen fordern. ${ }^{26}$

dies“ = „unterdessen“?). Dabei ist natürlich immer kritisch zu erwägen, ob wirklich bereits eine entsprechende Lexikalisierung vorliegt. Dasselbe Problem stellt sich für diese Konstruktion auch im Sinn für „über dieses“ im Sinn von „darüber“ (vgl. Jer 2,12). Zum generellen Problem siehe auch unten, Kapitel 7, Abschnitt 4.5.1 die Diskussion zu Kol 1,6.9.

24 GGNT 330a, Anmerkung (a). Vgl. hingegen die Beispiele bei Duden 1771.

25 Vgl. die Paraphrase von Lk 14,14 bei GGNT 330f: „Denn es wird dir vergolten werden, sobald die Gerechten aufstehen.“ Vgl. Duden 1771: „Wenn sich der Zucker aufgelöst hat, wird die Emulsion über die Brotscheiben gegossen.“; „Sowie die Masse glatt ist, wird sie in eine gebutterte Auflaufform gegossen.“

26 Die hier gebotene Diskussion kann vor allem im Großbereich der Kausalität als Explikation dessen verstanden werden, was Köppe und Kindt, Erzähltheorie, 51 zu diesem Thema schreiben. Auch die Verknüpfung über „mentale Einstellungen“ (vgl. Köppe und Kindt, Erzähltheorie, 58-61) könnte über weite Strecken in textgrammatische Kategorien überführt werden. Das zeigt etwa das von ihnen angeführte nicht-kausale Beispiel: „Im Mai war Peter pleite. Als im August die Jagdhütte seines Opas abbrannte, konnte er die Versicherungssumme einstreichen." Das verbindende Element sei hier der „Geldgewinn“ als Gegenstand der Hoffnung Peters. Textgramma- 
An dieser Stelle soll es nur darum gehen, einen knappen Überblick über die relevanten nicht-temporalen Konnexionen zu geben. Wichtig für die Analyse ist hierbei der Umstand, dass nicht alle nicht-temporalen Konnexionen sinnhafte Verbindungen konstituieren, die Erzählungen konstituieren könnten. Dies liegt grundsätzlich darin, dass „Faktivität“ eine grundlegende Dimension in der semantischen Beschreibung von Konnektorkonstruktionen darstellt. ${ }^{27}$

\subsection{Konditionale Konnexionen}

Zunächst ist die konditionale Konnexion zu besprechen. Liegt ein solches Verhältnis zwischen zwei Propositionen vor, so benennt die „Wenn“-Proposition „eine sachliche Voraussetzung,“ die „Dann“-Proposition die „fest damit zu verbindende sachliche Konsequenz." ${ }^{28}$ Als Konnektoren der konditionalen Konnexion fungieren hauptsächlich die subordinierenden Konjunktionen ci und ćóv, welche die Protasis („Wenn“-Satz) eines konditionalen Gefüges („Konditionalperiode“) einleiten. ${ }^{29}$ Das griechische unterscheidet verschiedene Konditionalgefüge aufgrund des Realitätsbezugs der Protasis.

Für Erzählungen auf den ersten Blick relevant erscheinen diejenigen Fälle, in welchen die Protasis mit $\varepsilon \dot{l}$ eingeleitet wird und ein Indikativ folgt ${ }^{30}$ (und kein ő $v$ in der Apodosis steht). ${ }^{31}$ Gerade in der älteren Literatur begegnet man immer wieder der Ansicht, zur Zeit des Neuen Testaments habe dieser - oft als „Realis“ bezeichnete - Fall des Konditionalsatzes die ursprüngliche Funktion, „lediglich die Annahme“ auszudrücken, weitestgehend verloren, ,indem es (wohl infolge

tisch würde man hier vermutlich eine adversative Konnexion postulieren, da die abschließende Proposition in einem Gegensatz zu einer rekonstruierbaren konditionalen Basis (,Wenn jemand pleite ist, bleibt er es auch.“) steht. Deutlicher wäre dies noch, wenn ein adversativer Konnektor integriert wäre: „,... konnte er jedoch die Versicherungssumme einstreichen.“ Andere von Köppe und Kindt genannten Aspekte sind von den konkreten außertextlichen Faktoren abhängig. Zumindest der Aspekt der durch den Erzähler vorgenommenen Bewertung soll im Folgenden jedoch zumindest schlaglichtartig berücksichtigt werden, denn neben lexikalischen Mitteln (vgl. das Beispiel des Adjektivs „bedauerlich“ bei Köppe und Kindt, Erzähltheorie, 59) kann eine Evaluation/Kommentierung des Erzählten auch durch spezifische Konnexionen vorgenommen werden.

27 Siehe Waßner, „Faktivität.“

28 GGNT 331b.

29 Für eine Übersicht über die konditionalen Konjunktionen siehe GGNT 280b.

30 Für den durch den Optativ gekennzeichneten „Potentialis“ vgl. GGNT 282.

31 Zum irrealen Fall siehe GGNT 284. 
des Gegensatzes zum Irrealis) vorwiegend in der Beziehung auf eine vorliegende oder behauptete Wirklichkeit gebraucht wird." ${ }^{\text {"32 }}$

Wäre dies zutreffend, so könnte man عỉ auch mit kausalem „da“ übersetzen. ${ }^{33} \mathrm{Da}$ in diesem Typ Konditionalperiode die „Schlussfolgerung ... als (logisch) notwendig hingestellt" wird, ${ }^{34}$ müsste man bei Vergangenheits- oder Gegenwartsbezug der Protasis auch den durch die Apodosis ausgedrückten Sachverhalt (und den der Protasis sowieso) als Elemente einer Erzählung, als EreignisSchilderungen betrachten.

Während es durchaus richtig ist, dass im NT sehr häufig davon ausgegangen werden kann, dass der Autor den in der Protasis ausgedrückte Sachverhalt als tatsächlich gegeben ansieht, ist dies aber durchaus nicht durchgehend der Fall. ${ }^{35}$ Die Tatsache, dass im NT die Bedingung häufig als erfüllt erscheint, ist daher nach Heinrich von Siebenthal als „kontextbedingt und nicht von der Art der Konditionalperiode abhängig“" zu betrachten. ${ }^{36}$

Eine Übersetzung mit kausalem „da“ ist in vielen Fällen zwar sachlich korrekt, ignoriert aber die Pragmatik des Textes. ${ }^{37}$ Konditionale Konnexionen werden hier daher nicht als Erzählungen konstituierend betrachtet. Dennoch ist die konditionale Konnexion für die narrative Vertextung wichtig. Denn die in ihr explizit gemachte Wenn-Dann-Beziehung liefert die Basis für die Großkategorie der „im weiteren Sinne kausalen Konnexionen.“38

\subsection{Kausale Konnexionen}

So wird beispielsweise in (im engeren Sinne) kausalen Konnexionen der potenzielle Sachverhalt des Wenn-Satzes als tatsächlich dargestellt. ${ }^{39}$ Bei der Kausalität handelt es sich nach Köppe und Kindt um den ,wichtigste[n] Typ einer sinnhaften Ereignisverknüpfung.“" ${ }^{\circ 0}$ Die wichtigsten Konnektoren im NT sind die

32 BDR 371.

33 Vgl. BDR 372.

34 GGNT 281a.

35 Vgl. Beispiele bei GGNT 281b. Siehe etwa Luk 11,19 für eine aus Sprecherperspektive eindeutig nicht erfüllte Bedingung.

36 GGNT 281a.

37 Siehe unten, Kapitel 15, Abschnitt 5.2 für zahlreiche Illustrationen, wie die Wahl der konditionalen und nicht der kausalen Konnexion das Kommunikat prägt.

38 GGNT 332. Vgl. Duden 1781.

39 Vgl. vor allem Duden 1782.

40 Köppe und Kindt, Erzähltheorie, 51. 


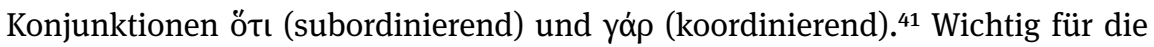
Suche nach narrativen Strukturen sind folgende Einschränkungen.

Erstens ist zu bachten, dass die kausale Konnexion sowohl nach dem Muster Grund-FOLGE als auch als Grund-AUFFORDERUNG-Relation vorkommt, ${ }^{42}$ wobei lediglich die erstere Unterkategorie für Erzählungen relevant ist. ${ }^{43}$

Zweitens ist die Ebene der Verknüpfung zu beachten. In der dem Alltagsverständnis folgenden Definition meint „Kausalität ... direkte physikalische Verursachung. “44 Nicht in allen kausalen Konnexionen liefert der Weil/Denn-Satz aber die Ursache für ein darauf folgendes Geschehen. In manchen kausalen Konnexionen wird vielmehr die umgekehrte, sogenannte „Symptomperspektive“ (und nicht die ihr entsprechende Sachverhaltsperspektive) eingenommen. ${ }^{45}$

Um zu verstehen, was damit gemeint ist, muss die zugrundeliegende konditionale Basis herangezogen werden. Wenn die beiden Teilsätze eines Konditionalgefüges einander gegenseitig bedingen (d.h., „genau dann, wenn ..., dann ...“), sind die Propositionen austauschbar: ${ }^{46}$

(Genau dann,) wenn ich diesen Euro heute spare, (dann) habe ich ihn morgen noch.

(Genau dann,) wenn ich diesen Euro morgen noch habe, (dann) habe ich ihn heute gespart.

Entsprechend kann auch die aus dieser Basis ableitbare kausale Konnexion zwei entgegengesetzte Perspektiven annehmen:

Weil ich diesen Euro gestern gespart habe, habe ich ihn heute immer noch.

Weil ich diesen Euro heute immer noch habe, habe ich ihn gestern gespart.

Der Kausalsatz gibt folglich an, auf welcher Grundlage eine bestimmte Sache ausgesagt wird, welche Evidenz dafür vorliegt. Da die zugrundeliegende konditionale Basis meist asymmetrisch ist (d.h.: es gäbe auch noch andere Wenn-Sätze, für die der Dann-Satz gälte), ${ }^{47}$ sind die resultierenden Schlüsse logisch nicht

41 Für eine vollständigere Übersicht siehe GGNT 333a.

42 GGNT 333b.

43 Siehe oben, Kapitel 3, Abschnitt 3.4.3.4.

44 Köppe und Kindt, Erzähltheorie, 51. Vgl. Köppe und Kindt, Erzähltheorie, 51-52 für eine Problematisierung der Definition.

45 Duden 1782.

$46 \mathrm{Vgl}$. Duden 1772, von wo auch das Beispiel übernommen wurde.

47 Ich könnte den Euro ja auch verschwenderisch ausgegeben haben, ihn heute aber bei einem weiteren Rauschkauf als Wechselgeld zurückerhalten haben. 
gültig, was ihrer Bedeutung in der alltäglichen Kommunikation jedoch keinen Abbruch tut. ${ }^{48}$

Für die Textdeutung ist die Unterscheidung der Symptomperspektive von der Sachperspektive von großer Bedeutung, wie das neutestamentliche Beispiel ${ }^{49}$ Lk 7,47 zeigt: ${ }^{50}$ „Ihre vielen Sünden sind vergeben. Denn sie hat viel geliebt“

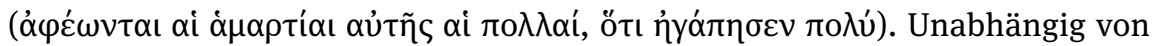
der eingenommenen Perspektive sind Sündenvergebung und Liebestaten hier als tatsächliche Geschehnisse ausgesagt. Die angenommene Perspektive macht jedoch einen großen Unterschied für die Rekonstruktion der Ereignisse:

Sachperspektive: Die Frau liebte zuerst, was im Anschluss Vergebung verursachte.

Symptomperspektive: Der Frau wurden zuerst die Sünden vergeben, was dann Liebestaten auf ihrer Seite auslöste.

Ein in der Deutung weniger umstrittenes paulinisches Beispiel wäre 1. Kor 10,5: „Aber Gott hatte an den meisten von ihnen kein Wohlgefallen, denn sie sind in

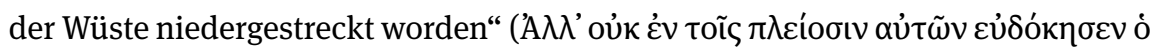

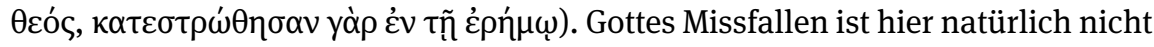
von seiner vorausgehenden Strafe verursacht.

Neben der unterschiedlichen Rekonstruktion der Ereignisfolge unterscheiden sich die Perspektiven auch in der Art und Weise, wie sie sich auf den ausgesagten Sachverhalt beziehen: Im zweiten Fall liegt nicht nur „Sachverhaltsbezug,“ sondern auch „Äußerungsbezug“ vor, ${ }^{51}$ der Kausalsatz begründet nicht primär ein Geschehen der erzählten Welt, sondern ein Element der Erzählung selbst, nämlich eine im Zuge des Erzählens gemachte Äußerung.

Man könnte daher argumentieren, dass sich ein solcher Kausalsatz nur graduell von „metadiskursiven“52 Bezügen („Ich nehme an, dass ihre Sünden vergeben wurden ...“) unterscheidet. Aus Symptomperspektive geäußerte kausale Konnexionen (Grund-FOLGERUNG statt Grund-FOLGE) ${ }^{53}$ sind somit eher als metanarrativ denn als Teil der Erzählung selbst zu werten. Auch wenn yó $\rho$ gegenüber ötı (dem Deutschen „weil“ vs. „denn“ entsprechend) überwiegend verwendet

48 Duden 1783.

49 Wir gebrauchen entsprechende Kausalsätze auch im Deutschen ständig, ohne dass uns auffallen würde, dass hier keine propositionale Verknüpfung vorliegt. Siehe dazu oben, Kapitel 4, Abschnitt 5.1 zu propositionalen Strukturen. In dieser Arbeit vgl. etwa oben, Kapitel 3, Abschnitt 3.3 den Satz „Ryans Definition ist prototypisch angelegt, da ...“

50 GGNT 277a. Vgl. auch GGNT 333c. Siehe dort auch zum Beispiel Lk 7,47.

51 Duden 1754-1755.

52 Vgl. Duden 1755-1756.

53 GGNT 322d. 
wird, um Äußerungen (nicht nur den Prädikatsinhalt des übergeordneten Satzes) zu begründen, ist zu Beachten, dass im Griechischen auch ǒtı recht häufig Äußerungsbezug aufweist. ${ }^{54}$

Im NT ist Äußerungsbezug zudem besonders häufig in kausalen Konnexionen, in welchen Aufforderungen gestützt werden (d.h. in Grund-AUFFORDERUNG-

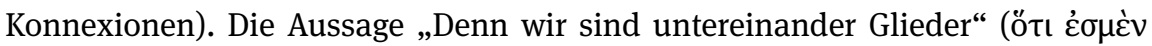
$\left.\dot{\alpha} \lambda \lambda \hat{n} \lambda \omega \nu \mu \varepsilon^{\prime} \lambda \eta\right)$ in Eph 4,25 begründet beispielsweise, weshalb die zuvor geäu-

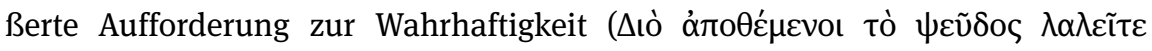

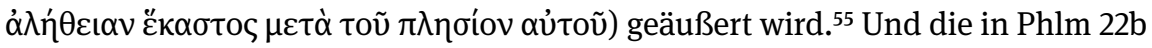
geäußerte und mit yó $\rho$ angeschlossene Hoffnung auf einen baldigen Besuch beim Adressaten begründet die Äußerung der zuvor in 22a ergehenden Aufforderung

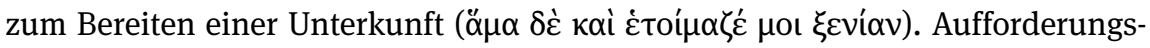
sätze werden hier jedoch ohnehin nicht als Ereignis-Repräsentation eingestuft, wie auch bereits oben in der ersten Einschränkung wiederholend angemerkt wurde.

\subsection{Konsekutive, modal-instrumentale und finale Konnexionen}

Auch jenseits der kausalen Konnexionen im engeren Sinn ist die konditionale

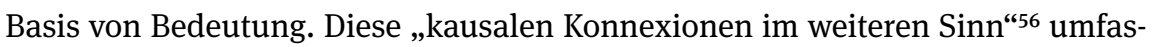
sen drei Unterkategorien:

(1) Bei der konsekutiven Konnexion wird im Gegensatz zur kausalen Konnexion (im strengen Sinn) eine Fokussierung auf das Dann-Element als Resultat des ebenfalls vorausgesetzten Wenn-Sachverhalts vorgenommen. ${ }^{57}$ Im HDK 2 wird dementsprechend betont, dass es sich bei kausalen und konsekutiven Konnektoren um zwei verschiedene „Kodierungsstrategien“ handelt, bei denen einmal durch den Konnektor das Antezedens markiert wird (,kausal i.e. S.“) und einmal das Konsequens („konsekutiv“). Wie im Deutschen scheint auch im Griechischen die Textfolge hier „ikonisch,“ dass also wie auf der Ebene der Sachverhalte hier die Folge nach dem Grund angeführt wird. Die häufig als kausale Adverbkonnek-

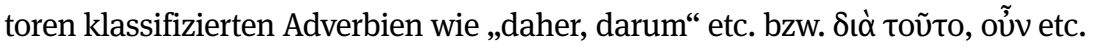
sollten als Markierungen einer konsekutiven Konnexion verstanden werden. ${ }^{58}$

54 GGNT 277a.

55 Vgl. auch GGNT 322d.

56 GGNT 323a. Vgl. auch Duden 1758.

57 GGNT 334.

58 GGNT 333a ist sich des Problems bewusst, wenn er schreibt, dass sich hier Kausales und Konsekutives „,berühren.“ Siehe Breindl, „Zusammenspiel,“ 71 für die problematische doppelte Zuordnung der Adverbien im Duden. 
(2) Im Fall einer modal-instrumentalen Konnexion wird die konditionale Basis als ein Mittel-ERGEBNIS-Verhältnis interpretiert. ${ }^{59}$ Stimmt das Ergebnis mit einer intentionalen Verwendung des Mittels überein, so kann man auch von einer Mittel-ZWECK-Konnexion sprechen. ${ }^{60} \mathrm{Zu}$ Abgrenzungsschwierigkeiten zwischen der konsekutiven und der modal-instrumentalen Konnexion kann es insbesondere dann kommen, wenn in der konsekutiven Konnexion „neben der Folge auch die Art und Weise des verursachenden Zustandes“ im Vordergrund steht. ${ }^{61}$

$\mathrm{Ob}$ bei dieser Konnexion überhaupt zwei verschiedene Sachverhalte angeführt werden, hängt nicht zuletzt davon ab, wie die zugrundeliegende modale ${ }^{62}$ bzw. instrumentale ${ }^{63}$ Angabe/Ergänzung konstruiert ist. Im Fall des adverbialen Partizips ist neben der Nennung „nähere[r] Begleitumstände“ etwa auch die Ausführung dessen möglich, „worin das Geschehen oder der Zustand genauer besteht.“64 Modale Konnexionen können innerhalb von Erzählungen daher auch als Mittel der repetitiv-spezifizierenden Narration desselben Ereignisses dienen.

(3) Die finale Konnexion übernimmt von der modal-instrumentalen Konnexion die Qualifizierung der Wenn-Proposition als Mittel, fokussiert aber auf „den verfolgten Zweck, das Motiv, ein zu erreichendes Ziel oder die angestrebte Wirkung einer Handlung. “65 Während also beim modal-instrumentalen Verhältnis die Protasis der konditionalen Basis sprachlich durch Konnektoren ausgewiesen wird, erscheint hier der die Finalität anzeigende Konnektor in dem Element, welches der Apodosis entspricht. Die kommunikative Gewichtung kann auf beiden Teilen der Konnexion liegen (MITTEL-Zweck bzw. Hinbewegung-ZIEL, wobei im letztgenannten Fall auch eine stärkere tempoale Komponente enthalten sein soll). ${ }^{66}$

Das folgende Beispiel ${ }^{67}$ in Abb. 22 illustriert das Verhältnis der drei KonnexionsTypen und deren Beziehung zur gemeinsamen konditionalen Basis.

\footnotetext{
59 GGNT 335.

60 GGNT 335b.

61 Duden 1790.

62 Für die (auch nicht satzwertigen) Konstruktionsmöglichkeiten siehe GGNT 259f.

63 Für die (auch nicht satzwertigen) Konstruktionsmöglichkeiten siehe GGNT 2591.

64 GGNT 231e.

65 So Duden 1791.

66 GGNT 352b. Vgl. auch unten, Abschnitt 4.1.

67 Vgl. zur modal-instrumentalen und zur finalen Konnexion Duden 1789 und 1791.
} 


\begin{tabular}{|l|l|l|}
\hline Konditionale Basis & Wenn wir heute sparen, & [dann] haben wir morgen mehr. \\
\hline $\begin{array}{l}\text { Modal- } \\
\text { instrumentale } \\
\text { Konnexion }\end{array}$ & $\begin{array}{l}\text { Dadurch dass/indem wir } \\
\text { heute sparen, }\end{array}$ & haben wir morgen mehr. \\
\hline $\begin{array}{l}\text { Konsekutive } \\
\text { Konnexion }\end{array}$ & Wir sparen heute, & sodass wir morgen mehr haben. \\
\hline $\begin{array}{l}\text { Finale } \\
\text { Konnexion }\end{array}$ & Wir sparen heute, & $\begin{array}{l}\text { damit wir morgen mehr haben/um } \\
\text { morgen mehr zu haben. }\end{array}$ \\
\hline
\end{tabular}

Abb. 22: Die gemeinsame konditionale Basis der kausalen Konnexionen im weiteren Sinn.

Neben den kausalen Konnexionen sind für narrative Vertextungsmuster vor allem die modal-instrumentalen und konsekutiven Relationen von großer Bedeutung. Ein Sachverhalt, der in die Zweck/Ziel-Proposition einer finalen Konnexion eingebunden ist, erfüllt demgegenüber die hier für Erzählungen geforderte Ereignis-Bedingung nicht. Denn in finalen Konnexionen wird die Perspektive des Agens der Mittel-Proposition eingenommen, von wo aus das Erreichen des Anvisierten noch aussteht. Das beabsichtigte Ereignis ist somit aus der eingenommenen Perspektive ein noch Zukünftiges und „ob das Ziel erreicht bzw. das Angestrebte verwirklicht wird oder nicht, bleibt innerhalb dieser Konnexion unerwähnt ... Bei der modal-instrumentalen Konnexion scheint die Erfüllung des Zwecks wesentlich. “68 Bei der konsekutiven Konnexion ist dies im Einzelfall $\mathrm{zu}$ entscheiden, zumal in der Koine nicht mehr konsequent zwischen Indikativ für tatsächliche und Infinitiv für nur gedachte Folge nach $̋ ّ \tau \tau$ unterschieden wird. ${ }^{69}$ Heinrich von Siebenthal rechnet die selten belegte beabsichtigte Folge der finalen Konnexion $\mathrm{zu}^{70}$

Zu beachten ist, dass die Einteilung von Duden/GGNT nicht unumstritten ist. Im HDK 2 (vgl. Abb. 8) wird die „modale“ Kategorie als zu heterogen betrachtet,

68 GGNT 336b. Entsprechend merkt Breindl, „Semantische Klassifikation,“ 267 auch an: „Die instrumentalen Verknüpfungen präsentieren sich nur auf einen oberflächlichen Blick als Konversen der finalen ... Sie unterscheiden sich von diesen aber genau in der Faktizität beider Argumente."

69 Siehe dazu unten, Kapitel 6, Abschnitt 7.2.1.

70 GGNT 221b. Vgl. CGCG 46.9, wo das ,intended result“ von Finalsätzen abgegrenzt wird, da in jenen „the nature of consequence between the matrix clause and the subordinate clause“ nicht spezifiziert werde, während mit $\ddot{\sigma} \sigma \varepsilon$ und Inf. ausgesagt werde, dass ,an action ... is performed in such a way that it (naturally) leads to the intended result.“ 
„um im Rahmen der Systematik einen angemessenen Platz zu finden.“71 Es wird stattdessen neben dem konversen Paar „kausale und konsekutive Relationen“ zwischen der „instrumentalen“ (Markierung des Antezedens) semantischen Klasse und der „finalen“ (Markierung des Konsequens) unterschieden. ${ }^{72}$ Die üblicherweise als „modal“ klassifizierten Begleiterscheinungen werden als „komitative“ Unterklasse der additiven Konnektorenverhältnisse klassifiziert: ${ }^{73}$

Komitativität [bedeutet] zunächst nicht mehr, als dass ein Sprecher eine Situation als mit einer anderen einhergehend, als von ihr „,begleitet“ konzipiert (,p, und dabei q'). Komitativität ist damit die am wenigsten spezifische der adverbialen Relationen, und ihre Beschreibung als „Begleitumstand“ in der traditionellen Grammatik ist oft genug identisch mit der Beschreibung von Adverbial schlechthin.

Das im Deutschen mit „dabei,“ „indem“ oder „wobei“ eingeleitete Konnekt weist dabei eine ganz unterschiedlich starke Involviertheit in das Hauptgeschehen und entsprechend eine stark variierende Rolle (Werkzeug, Begleitumstand, Material, Partner etc.) auf. ${ }^{74}$ Hier besteht noch Bedarf und Potenzial für die Forschung an altgriechischen Texten.

\subsection{Konzessive Konnexionen}

Von den bisher besprochenen Fällen „kausaler Konnexionen im weiteren Sinn“ lässt sich die weitere Untergruppe der adversativen und konzessiven Konnexionen abgrenzen, denen ebenfalls ein Wenn-Dann-Verhältnis zugrunde liegt, die das Verhältnis aber „aus einer gegenläufigen Perspektive [versprachlichen].“75

Diese Gegenläufigkeit lässt sich besonders klar im Fall der konzessiven Konnexion erkennen. ${ }^{76}$ Grundlegend ist eine Wenn-Dann-Beziehung vorausgesetzt, es wird also von einer Erwartungshaltung ausgegangen, welche die Frage betrifft, was aus dem Erfülltsein einer bestimmten Voraussetzung (mit unterschiedlich großer Sicherheit) folgen würde.

In der konzessiven Konnexion wird nun das Ereignis der zugrundeliegenden Protasis als gegeben vorausgesetzt, jedoch zugleich das der Erwartungshaltung entgegengesetzte Ausbleiben des in der Apodosis enthaltenen Geschehens. Es

71 Breindl, „Semantische Klassifikation,“ 252.

72 Vgl. Breindl, „Semantische Klassifikation,“ 263.

73 Breindl, „Additiv basierte Konnektoren,“ 569.

74 Breindl, „Additiv basierte Konnektoren,“ 570.

75 Duden 1781.

76 Vgl. zu dieser GGNT 339 und Duden 1800-1802. 
entsteht eine Einräumung-NICHTERWARTETES-Relation, wobei die Konnektoren

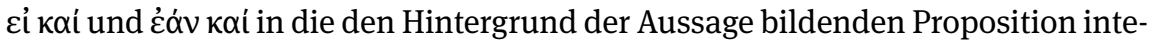
griert sind. ${ }^{77}$

Ein erster Aspekt, der für die narratologische Analyse von Bedeutung ist, stellt die Frage dar, in welchem Verhältnis das NICHTERWARTETE zur Realität steht. ${ }^{78}$ Recht häufig steht in konzessiven Konnexionen in der NICHTERWARTETESProposition schlicht die Verneinung der zugrundeliegenden Apodosis. Die narratologische Bewertung solcher Konnexionen muss je nach dem hierbei zugrundeliegenden Muster unterschiedlich ausfallen:

(a) Im Normalfall wird zwar auf eine denkbare bzw. sogar erwartete Ereignisfolge verwiesen - diese aber gerade nicht erzählt. Diese Art des konzessiven Verhältnisses konstituiert somit nicht wirklich eine Erzählung, sondern stellt sogar eine Art „Anti-Erzählung“ dar. So liegt 2. Kor 10,3 die konditionale Basis „Wenn jemand im Fleisch wandelt, dann kämpft er auch dem Fleisch gemäß.“ zugrunde. Paulus räumt die Protasis ein („Denn obwohl wir im

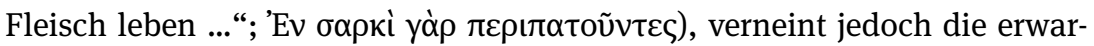

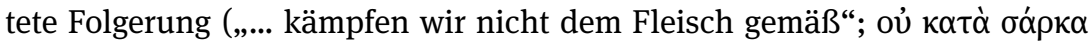

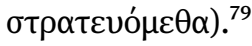

(b) Eine Erzählung tatsächlichen Geschehens kann jedoch dann vorliegen, wenn in der zugrundeliegenden konditionalen Basis die Apodosis selbst in der Verneinung eines Sachverhalts besteht. So liegt Röm 1,32 das folgende konditionale Verhältnis zugrunde: „Wenn jemand weiß, dass ein bestimmtes Handeln todeswürdig ist, dann praktiziert er es nicht. “ Das NICHTERWARTETE besteht hier gerade in der Bestätigung, dass die Apodosis doch zutrifft: Obwohl „sie“

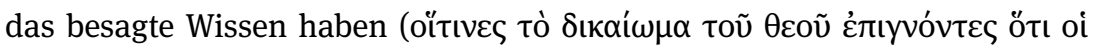

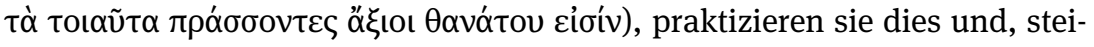
gernd (d.h. noch unerwarteter) haben auch noch Wohlgefallen an denen,

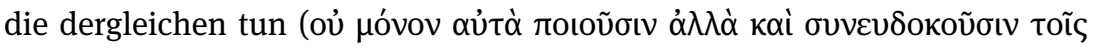
$\pi \rho \alpha ́ \sigma \sigma o v \sigma เ v)$.

(c) Auch wenn in der zugrundeliegenden konditionalen Basis die Apodosis in einer affirmativen Aussage besteht, ist es schließlich unter bestimmten Umständen möglich, dass das NICHTERWARTETE entgegen der oben aufgestellten Regel ein tatsächliches Geschehen aufweist. Denn das Nichterwartete kann auch ausführlicher entfaltet werden, indem es durch

77 Im Fall des konzessiven Partizips stellt dieses die Proposition selbst dar.

78 Gesondert zu betrachten sind im Deutschen die Konstruktionen mit „Wenn [...] auch,“ die nämlich Einräumungen mit Äußerungsbezug bezeichnen. Vgl. bei Paulus Gal 1,8, 6,1 und Röm 9,27. Siehe Burton 285 zu diesem Zukunftsbezug.

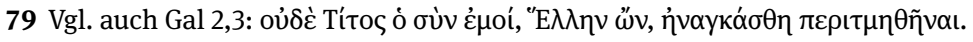


zwei Propositionen zum Ausdruck gebracht wird, die in einem adversativen Negativum-POSITIVUM-Verhältnis stehen (siehe dazu weiter unten, Abschnitt 3.6): „Obwohl X, nicht Y, sondern Z.“ Auf diese Weise wird neben der Einräumung (X) noch ein weiteres (unerwartetes) Ereignis (Z) festgehalten - welches auf der höheren Ebene des Propositionalgefüges zum NICHTERWARTETEN gehört. Denn vorausgesetzt ist einerseits die Erwartung, dass wenn X, dann Y, aber andererseits auch, dass wenn Y, dann nicht Z. Dadurch dass X zwar eintritt, jedoch nicht wie erwartet Y folgt, wird ebenfalls unerwartet der Weg frei für Z. Dieses Muster liegt vollständig etwa in 1. Thess 2,5-7 vor: ${ }^{80}$ Obwohl die Apostel als solche gewichtig hätten auftreten können (V.

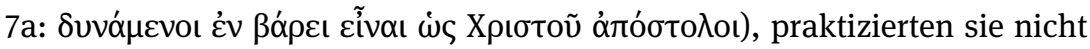
ein entsprechendes Verhalten (V. 5-6), sondern verhielten sich ganz anders (V.

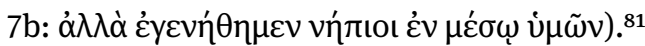

(d) Dieses Muster liegt oft in verkürzter Form vor, wobei das „nicht Y“-Element ausgelassen wird. Es fehlt also die explizite Schilderung des Nichteintretens der Apodosis, sodass auf die Einräumung (,Obwohl X“) direkt ein weiteres tatsächliches Geschehen (,Z“) folgt, welches an die Stelle des erwarteten Sachverhalts tritt, der im Hintergrund bleibt. Dies ist etwa der Fall in 1. Kor 9,19. Die Basis lautet: „Wer allen gegenüber frei ist, behält diesen Status auch bei.“ Paulus greift die Protasis durch das konzessive Partizip auf („Obwohl ich allen gegenüber frei bin“;

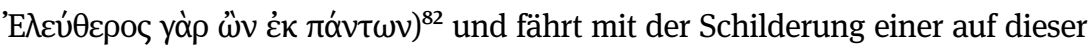
Grundlage unerwarteten Handlung fort: „Ich habe mich allen zum Sklaven

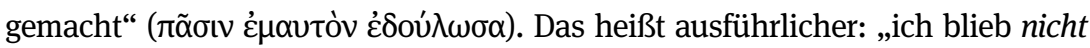
(wie zu erwarten wäre) allen gegenüber frei, sondern .... ${ }^{83}$

Ein weiterer grundsätzlicher Aspekt, der im Kontext der erzähltheoretischen Analyse im Hinblick auf konzessive Konnexionen eine Rolle spielt, ist der Umstand, dass dieser Typ Konnexionen mit Erwartungshaltungen spielt. Für ein Verständnis der Erzählung in ihrem pragmatischen Kontext ist daher äußerst relevant, zu bestimmen, um wessen Erwartungshaltung es sich handelt - ob der Autor hier also etwa auf allgemeines Weltwissen zurückgreift, ob er die generelle Gültigkeit der konditionalen Basis selbst vertritt oder ob er hier spezifisch die zu

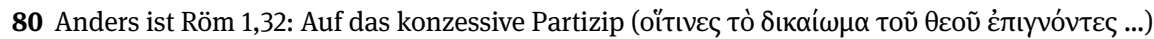
folgt oủ hóvov ... $\dot{\alpha} \lambda \lambda \dot{\alpha}$, also eine additive Konnexion. Es werden folglich $z w e i$ unerwartete Ereignisbündel geschildert.

81 Zur Syntax siehe unten, Kapitel 12, Abschnitt 2.2.

82 Für die vor allem in der deutschsprachigen Exegese anzutreffenden alternativen Ansichten siehe ausführlich Coppins, ,Juxtaposition.“

83 Ebenso Phlm 8-9. Vgl. auch GGNT 339 zu 1. Thess 1,6. 
korrigierende Perspektive der Leserschaft oder einer dritten Gruppe einnimmt. Im Hinblick auf das obige Beispiel 2. Kor 10,3 ist beispielsweise auffällig, dass durch den vorangehenden Vers 2 eine Fokalisierungsinstanz eingeführt wird, für die der „fleischliche Kampf“ wohl gerade die erwartbare Fortsetzung wäre: „... die von

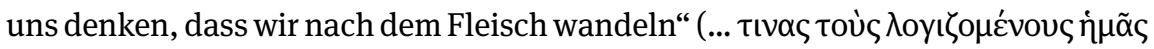

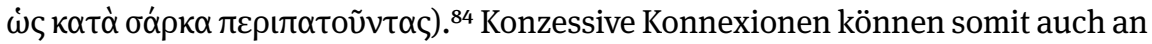
meta-narrative Kommentare des Erzählers heranreichen, in welchen dieser eine Evaluation des von anderen mehr oder weniger explizit Erzählten bietet.

\subsection{Adversative Konnexionen}

Weniger transparent als im Fall der konzessiven Konnexion ist der Bezug zu einer konditionalen Basis meist bei adversativen Propositionalbeziehungen, ${ }^{85}$ da sie einen „grundsätzlich additiven Charakter“ aufweisen. ${ }^{86}$ Der Konnektor ist dabei meist in die zweite Proposition integriert, welche im Gegensatz zur ersten steht. ${ }^{87}$

Im Fall der Negativum-POSITIVUM-Relation dient der verneinte Sachverhalt als Kontrastfolie für die positiv formulierte Proposition (i.d.R. eingeleitet durch „sondern“; $\alpha \lambda \lambda \alpha \dot{\alpha}$ ). Hier wird streng genommen also nur ein Ereignis festgehalten, die Konnexion selbst erfüllt also noch nicht die Minimaldefinition einer Erzählung.

Durch die ADVERSATIV-KERN 1-ADVERSATIV-KERN 2-Reihung (oder, im Fall einer unterschiedlichen Gewichtung, der Kern-KONTRAST-Relation) ${ }^{88}$ können hingegen durchaus aufeinander folgende Ereignisse erzählt werden, wobei das zweite Element mit unterschiedlicher Deutlichkeit an den Sachverhalt der ersten Proposition oder eher eine implizierte Dann-Proposition anknüpft. ${ }^{89}$

In Gal 1,13-14 liefert Paulus beispielsweise eine Erzählung seines früheren

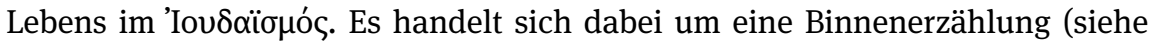

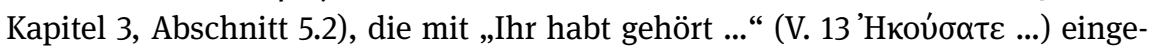
leitet wird. Das „Aber“ ( $\delta \varepsilon \dot{\varepsilon})$ in V. 15 „widerspricht“ weder dieser Einleitung (so

84 V. 3-6 torpediert allerdings nicht nur diese Erwartungshaltung, sondern nimmt auch stillschweigend eine Modifikation der Voraussetzung vor: Der Wandel findet im Fleisch statt, eine tatsächliche „Einräumung“ liegt also wohl aus Sicht der Kritiker gerade nicht vor.

85 Vgl. zu diesen GGNT 338. Siehe auch Duden 1793-1799.

86 Duden 1798.

87 GGNT 338b.

88 Vgl. zu letzterer etwa 1. Kor 9,24: „Sie laufen zwar alle, doch nur einer erhält den Siegespreis“

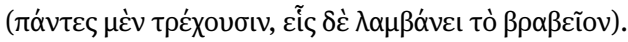

89 Vgl. GGNT 338d. 
als würde nun eine Alternativ-Schilderung desselben Zeitraums geboten, welche das Gehörte korrigieren würde) noch dem gegen Ende von V. 14 beschriebenen Eifer. Noch weniger kontrastiert es freilich den Entschluss Gottes, Paulus seinen Sohn zu offenbaren, mit dieser Vorgeschichte. Dieses Ereignis des Offenbarungsbeschlusses stellt lediglich (durch ö $\tau$ markiert) einen temporalen Bezugspunkt her zu dem, was in V. 16b-17 an Bewegungen des Paulus verneint und erzählt wird. Die zugrundeliegende konditionale Basis ist also wie folgt $\mathrm{zu}$ identifizieren: „Wenn man über jemanden eine Biographie wie in V. 13-14 erzählt bekommt, dann würde man erwarten, dass diese Person auch in gänzlichen neuen Umständen (vom gesetzestreuen Juden zum Völkerapostel!) dem alten Muster folgt.“ Der eigentliche Kontrast besteht also zwischen den selbstständigen Reisebewegungen des Paulus und dem Verhalten, das man von ihm als berufenem Apostel aufgrund seiner früheren Orientierung an anderen Bezugsgrößen erwarten hätte können. ${ }^{90}$

\subsection{Restriktive Konnexionen}

Diejenigen (nicht-temporalen) Konnexionen, welche nicht im weitesten Sinne kausal sind, sind für die narrative Vertextung weniger bedeutsam. Sie lassen sich in (a) spezifizierende und (b) vergleichende Verknüpfungen unterteilen. ${ }^{91}$

$\mathrm{Zu}$ den (a) spezifizierenden Relationen gehört die restriktive Konnexion, bei welcher eine „Äußerung in ihrer Gültigkeit eingeschränkt“ wird.92 Es werden also nicht zwei Ereignisse geschildert, sondern es wird lediglich eines näher bestimmt. So ergeht in Röm 12,18 eine Aufforderung zum Leben in Frieden „mit

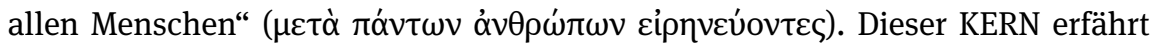

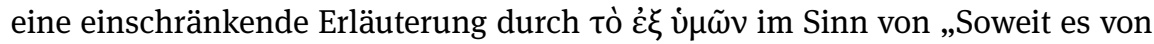
euch abhängig ist."93

Ist der KERN selbst verneint, so findet durch die „Einschränkung“ die eigentliche Aussage des Geschehens statt. Vergleiche hierzu etwa Gal 2,6-10, wo zunächst ein bestimmter Typ Ereignisse verneint wird: „... die Angesehenen

90 Der in V. 14 sehr ausführlich ausgestaltete relationale Aspekt des ehemaligen Netzwerks

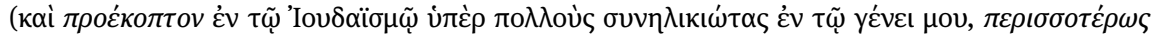

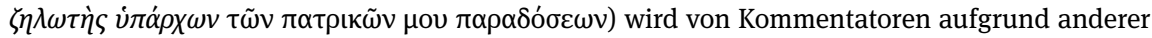
interpretativer Schwerpunktsetzungen oft nicht ausreichend wahrgenommen. Vgl. ausführlicher unten, Abschnitt 5.1.2.2.

$91 \mathrm{Zu}$ den rein additiven Konnektoren siehe etwa unten, Abschnitt 5.1.2 und Kapitel 12, Abschnitt 2.3.2. Siehe bereits grundsätzlich oben, Kapitel 4, Abschnitt 8.2.3.

92 GGNT 342b.

93 GGNT 342c. 


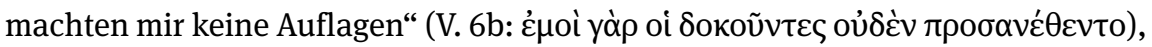
während mit $\mu$ óvov angeschlossen dann diese pauschale Aussage wieder korrigiert wird: ${ }^{94}, \ldots$ - nur sollten wir der Armen gedenken“ ( $\mu$ óvov $\tau \tilde{\omega} \nu \pi \tau \omega \chi \tilde{\omega} \nu$ ǐv $\alpha$ $\mu \nu \eta \mu \nu v \varepsilon u ́(\omega \mu \varepsilon v) .{ }^{95}$

\subsection{Explikative Konnexionen}

Der zweite spezifizierende Konnexions-Typ ist die explikative Konnexion. Es können hier verschiedene propositionale Beziehungen unterschieden werden, ${ }^{96}$ die in der Regel jedoch die Erzählung nicht vorantreiben, sondern eher zusätzliche Details zum im KERN geäußerten Ereignis liefern. ${ }^{97}$

Eine explikative Proposition knüpft häufig auch nur an einen Teil der vorangehenden Proposition, „ein einzelnes Konzept bzw. eine gemeinte Sache,“98 an. Auch hierdurch kann Kohärenz innerhalb einer Erzählung gestiftet werden:

(1) In der SACHE-Beschreibung-Relation wird ein bereits bekanntes Konzept weiter ausgeführt. In diesem Zug kann beispielsweise eine Rückblende geboten werden (vgl. Kapitel 11, Abschnitt 3 zum Aspekt der Ordnung) oder auch eine Charakterisierung des Agens der übergeordneten Proposition. Hierdurch kann auch ein der konzessiven Konnexion ähnlicher Effekt erzielt wird, wie etwa in Gal 1,23: „Er verkündigt nun den Glauben, den er

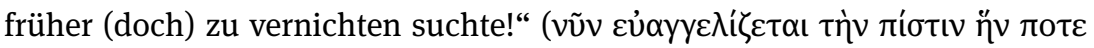
غ́лó $\rho \theta \varepsilon \mathrm{l}) .{ }^{99}$

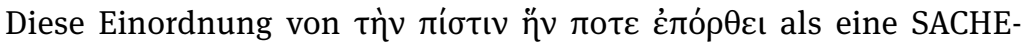
Beschreibung-Konnexion setzt voraus, dass es sich beim Relativsatz um ein nichtrestriktives Attribut handelt. ${ }^{100}$ Dass oft ohne Diskussion des

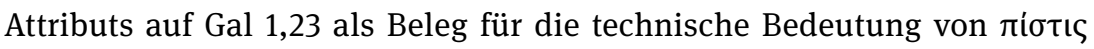
als Gesamtheit der christlichen Botschaft verwiesen wird, ${ }^{101}$ ist so gesehen

94 Zum Äußerungsbezug dieser Konnexionen siehe GGNT 342b.

95 Zum ìv siehe unten, Kapitel 14, Abschnitt 4.2.1.

96 Vgl. GGNT 341b.

97 Vgl. etwa 1. Kor 15,38: Im KERN steht das Ereignis der Gabe einer Gestalt entsprechend Gottes

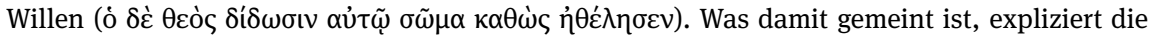

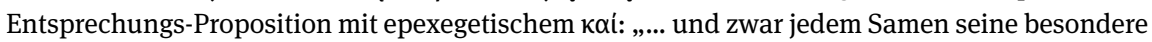

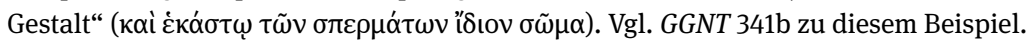

98 GGNT 341c.

99 Vgl. für weitere Beispiele GGNT 319a.

100 GGNT 260a, Anmerkung 12.

101 Vgl. etwa Schliesser, „Faith,“ 48. 
nicht unproblematisch. Diese Einordnung muss vielmehr erst aus der pau-

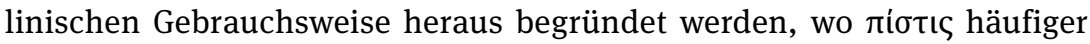
den spezifisch christlichen Glauben bezeichnet (z. B. Gal 3,23), also nicht im Sinn einer „Glaubensrichtung“ gemeint ist. Ansonsten könnte der Rela-

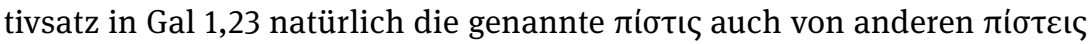

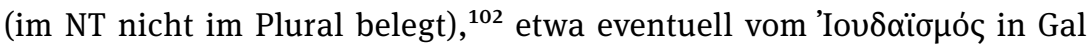
1,13.14, abgrenzen. $\mathrm{Zu}$ übersetzen wäre dann: „Er verkündigt nun denjenigen Glauben, welchen er früher zu vernichten suchte.“ ${ }^{103}$ Bei propositionswertigen Attributen dieser Art liegt eine andere Art der explikativen Konnexion vor, da hier eine Sache identifiziert wird. (Vgl. für ein ähnlich gelagertes Problem beim ersten Vorkommnis desselben Verbs $\pi о \rho \theta \varepsilon \dot{\varepsilon} \omega$ in

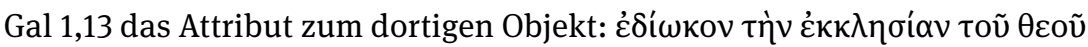

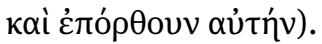

(2) In dieser SACHE-Identifizierung-Beziehung wird durch die zweite Proposition erläutert, welche Größe überhaupt gemeint ist. Für den Textzusammenhang haben solche Relationen ähnliche Funktion wie phorische und deiktische Funktionswörter. Wenn Paulus den Philippern in Phil 1,30 zusi-

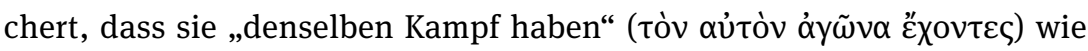

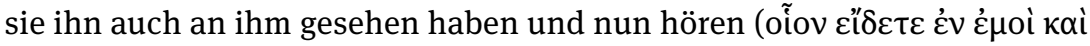

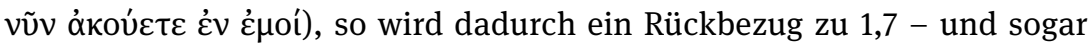
über den Text hinaus zur dem Text vorausgehenden Erfahrung - vorgenommen. ${ }^{104}$

Abzugrenzen von den bisher besprochenen Fällen, in welchem nur auf einen Aspekt der übergeordneten Proposition Bezug genommen wird, sind die explikativen KERN-Kommentar/Parenthese-Relationen. Hierbei ist die erklärende Proposition meta-textlich einzuordnen. ${ }^{105}$ Innerhalb eines Textabschnitts, der ansonsten recht eindeutig narrativ vertextet ist, liegt eine solche Beziehung etwa in Gal 1,20 vor, wo zwischen die Schilderung des Besuchs in Jerusalem (V. 19) und die Reise durch Syrien und Zilizien (V. 21) aus der Sicht des erzählenden Ichs die Bemerkung eingeschoben ist: „Siehe, bezüglich dessen was ich schreibe,

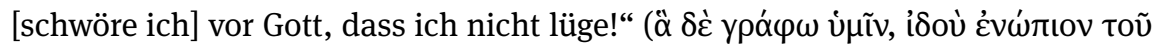

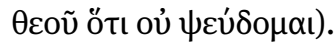

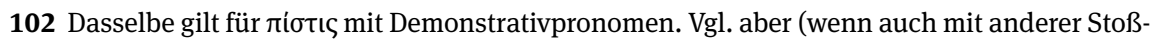

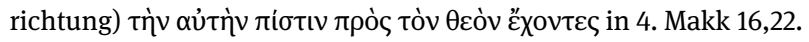

103 Vgl. Duden 1654-1655 zu den restriktiven/nichtrestriktiven Relativsätzen im Deutschen.

104 Vgl. zur Referenz Hawthorne, Philippians, 77.

105 GGNT 341b. 


\subsection{Vergleichende Konnexionen}

Diese Durchbrechung der Erzählebene ist auch typisch für (b) vergleichende Konnexionen. ${ }^{106}$ Im Normalfall der komparativen Konnexion ${ }^{107}$ kann eine Erzählung etwa vom Erzähler dadurch einer gewissen Bewertung zugeführt werden, dass die Ereignisfolge mit einem anderen Geschehen verglichen wird.

In Gal 3,6 wird zwar das zum Vergleich herangezogene Element aus Gen 15,6

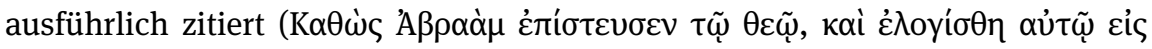

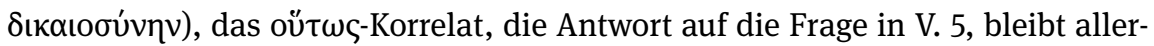
dings implizit. Bei bekannter Bezugs-Erzählung kann dieser Vergleich auch ins-

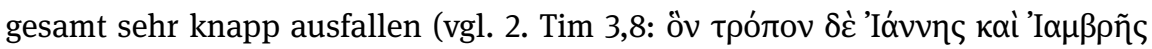

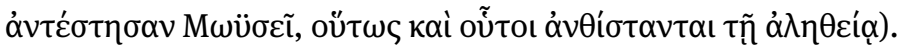

Beim KERN muss es sich freilich nicht unbedingt um erzählte Ereignisse handeln. So ist das ausführlich ausgestaltete vergleichende Element in Eph

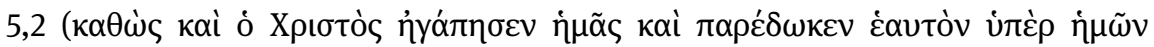

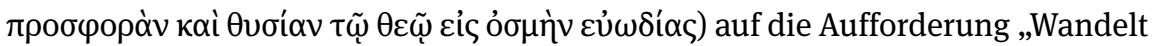

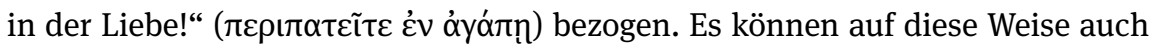
einander entsprechende deskriptive Passagen verknüpft werden. ${ }^{108}$

\section{Temporale Ordnung bei nicht-temporalen Konnexionen}

\subsection{Nicht-temporale Konnexionen mit zusätzlichem Zeitfokus}

Die vom Erzähler gemeinte temporale Ordnung ist auch in Konnexionen, die nicht primär Chronologisches ausdrücken, meist klar ersichtlich. ${ }^{109}$ Dies liegt teilweise an den Konnexionen selbst: So geht in der tatsächliche Ursächlichkeit

106 Wie auch die Kategorie der „modalen“ Relationen (siehe oben, Abschnitt 3.4), wird im HDK 2 diese semantische Klasse nicht mit in die Systematik aufgenommen. $\mathrm{Zu}$ den Gründen siehe Breindl, „Semantische Klassifikation,“ 252-253. Vgl. Breindl, „Einleitung,“2-3.

107 Der Spezialfall der proportionalen Konnexion scheint bei Paulus nicht belegt. Zumindest legt dies eine Suche nach den bei GGNT 345a gelisteten Konnektoren nahe. Im Fall der proportionalen Konnexion sind zwei Sachverhalte parallel-graduierend aufeinander bezogen. Im NT ist der Gebrauch innerhalb eines Erzähltextes durch Mk 7,36 belegt: „Aber je mehr er es

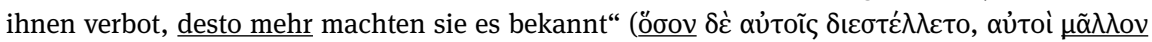

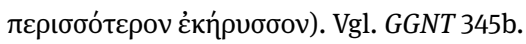

108 Vgl. etwa 1. Kor 7,22 mit ó $\mu o i ́ \omega s$.

109 Vgl. Zifonun, „Textkonstitutive Funktionen,“ 318: „(Nicht-erste) Textsätze, in denen keine expliziten Mittel der temporalen Verbundenheit und keine Mittel zur absoluten Zeitreferenz auftreten, sind als implizit temporal verbunden zu interpretieren.“ 
ausdrückende kausalen Konnexion die Ursache der Folge voraus. Ganz ähnlich ist die (finale) Hinbewegung-ZIEL- und die (konsekutive) GeschehenRESULTAT-Konnexion mit einem „Zeitfokus“ ausgestattet. ${ }^{110}$

Die modal-instrumentale Konnexion kann entsprechend der großen Bandbreite der zugrundeliegenden modalen und instrumentalen Näherbestimmungen vielfältige zeitliche Relationen von Sachverhalten aufgreifen. Typisch ist allerdings Gleichzeitigkeit - notwendigerweise dann, wenn durch ein modales Partizip das in der KERN-Proposition Gemeinte lediglich nochmals aufgegriffen und in anderen Worten expliziert wird. In einigen Fällen scheint beim modalen Partizip jedoch auch etwas gemeint sein, das zeitlich hinter die übergeordnete Proposition zurückreicht. ${ }^{111}$ Der Übergang zum Kausalen ist hierbei nicht immer klar zu erkennen. ${ }^{112}$

\subsection{Durch Erzählungen im Kontext zur Verfügung gestellte temporale Ordnung: Beispiel 1. Kor 8,10-11}

Äußerst relevant ist im Hinblick auf die modal-instrumentalen Konnexion aus narratologischer Sicht zudem die recht häufig zu beobachtende Auflösung des

110 GGNT 352b.

111 Vgl. das Beispiel Eph 6,14, welches Wallace, Grammar, 629 wie folgt erklärt: „Sometimes means blends imperceptibly into cause, especially with aorist participles. In such instances, the participle may be used for an action that is both antecedent and contemporaneous to the controlling verb.“ Er übersetzt entsprechend: „Stand, by having girded your loins with truth.“ Die Stelle wäre für Wallace weniger problematisch, wenn er bei seiner Unterscheidung von „of manner“- und „of means“-Partizipien - wobei letztere das Geschehen des Hauptverbs näher erklärten und erstere „extra color“ hinzufügten - die erstgenannte Kategorie nicht auf emotionale Begleitumstände beschränken würde (vgl. Wallace, Grammar, 627-631). Siehe auch unten, Kapitel 12, Abschnitt 2.3.2 die Diskussion zu 2. Thess 3,7b-8. Das Verhältnis der Situationszeiten von finitem Verb und Partizip ist in den Grammatiken noch nicht ausreichend geklärt. Vgl. etwa das fragwürdige „coincident aorist participle“ in CGCG 52.42. Grundlegende Thesen finden sich bei Bary und Haug, „Temporal Anaphora.“

112 Vgl. im Deutschen:

„Dadurch dass ich den ganzen Tag arbeitete, wurde ich immer müder.“

„Dadurch dass ich den ganzen Tag arbeitete, war ich am Feierabend müde.“ „Weil ich den ganzen Tag gearbeitet hatte, war ich am Abend müde.“
Hier stehen zwei parallel zueinander verlaufende Prozesse nebeneinander.

Das Mittel geht zeitlich dem ERGEBNIS voraus bzw. in dieses über.

Der abendliche Zustand wird kausal auf die Tätigkeit tagsüber zurückgeführt. 
temporalen Fokus in der Zusammenschau von Ereignissen, nachdem die zeitliche Beziehung im Kontext bereits spezifischer zum Ausdruck kam.

So wird in 1. Kor 8,10a zunächst in einem prospektiven Konditionalsatz durch ópó $\omega$ und AcP ein gleichzeitiges Geschehen angesprochen: ${ }^{113}$ Im Blick ist der

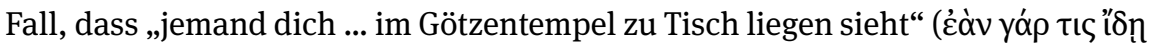

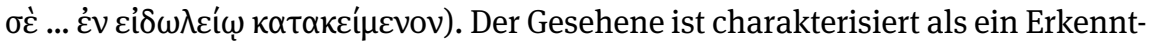

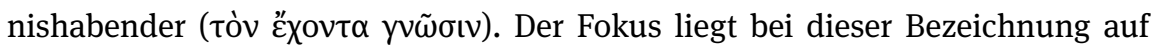
dem inhaltlichen Aspekt des Wissens, ${ }^{114}$ also auf einem mentalen Zustand, der mit dem Essen einhergeht. Zugleich ist aber auch klar, dass diese entscheidende theologische Erkenntnis (vgl. 8,4) einen entsprechenden Moment des Erkennens voraussetzt, denn nicht alle - einschließlich des Beobachters - „haben“ dieses Wissen (vgl. 8,7). In der Folge (8,10b) des im Konditionalsatz erwogenen Beobachtungs-Geschehens könnte der Beobachter zum Götzenopferfleisch verleitet werden, obwohl er selbst die Erkenntnis nicht verinnerlicht hat.

Der folgende Vers 11 ist nun in mehrfacher Hinsicht aus narratologischer Perspektive interessant. Erstens lässt sich hier mustergültig erkennen, wie der zuvor skizzierte Ablauf in einer ERGEBNIS-Mittel-Konnexion zusammengefasst wird, in welcher nicht mehr die Sequenz im Mittelpunkt steht, sondern nur noch die Relation der beteiligten „Akteure“: 115 „Dadurch dass du Erkenntnis erlangt hast (... غ́v Tñ

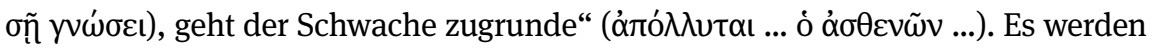
also zeitlicher Anfangspunkt (der Moment des Erkennens der einen Person) und Endpunkt (das Zugrundegehen der anderen Person) eines zuvor ausführlich skizzierten Ablaufs aufgegriffen und ohne die Zwischenschritte und ohne temporalen Fokus aufeinander bezogen. ${ }^{116}$

Zweitens lässt sich an dieser Passage die Vielgestaltigkeit narrativer Vertextungen illustrieren, da hier dieselbe Handlung unmittelbar aufeinander folgend auf ganz unterschiedliche Weise entfaltet wird. Dabei wird das Prinzip der ,pragmatischen Entlastung“ (siehe oben, Kapitel 4, Abschnitt 5.2) der Grammatik-Seite des Textes besonders gut nachvollziehbar: Klassifikatorisch könnte 1. Kor 8,11 wohl durchaus als Miniaturerzählung behandelt werden, denn der gemeinte zeitliche Zusammenhang ist aus dem Kontext leicht zu erschließen, da dieser eine deutlicher temporal fokussierte Inbezugsetzung der Ereignisse aufweist, als sie in der „Zusammenschau“ der ERGEBNIS-Mittel-Relation in Isolation erkennbar

113 Es wird nicht „erzählt,“ da der Konditionalsatz in seiner Beziehung zur Wirklichkeit offen ist. Siehe aber unten, Kapitel 14, Abschnitt 5.2.

$114 \mathrm{Vgl}$. 1. Kor 8,1. Siehe LN 28.17: ,the content of what is known.

115 GGNT 335b.

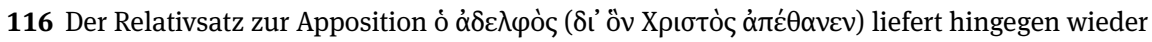
eine (temporale) Rückblende. 
wäre. Dass die Minimalerzählung als solche erkannt werden kann, liegt daran, dass hier eine dem Lesern bereits bekannte Handlung prägnant nacherzählt wird. Mit dieser Option ist natürlich auch da zu rechnen, wo die Bezugs-Erzählung nicht im Text selbst vorliegt, den Erstlesern aber bekannt sein könnte.

Drittens unterstreicht der Beispieltext, wie sehr sich die Frage nach impliziten Erzählungen bei der Beschäftigung mit expliziten narrativen Vertextungen aufdrängt. Es fällt schwer, in der exegetischen Analyse nicht von „Erzählungen“ (sondern lediglich von „Ereignisfolgen“ etc.) zu sprechen. Dies gilt insbesondere für V. 11, wo lediglich im Kontext deutlich wird, dass trotz des Indikativs lediglich eine hypothetische Erzählung vorliegt, da das im Hintergrund stehende Geschehen im vorausgehenden Text wegen des Konditionalgefüges lediglich ein Erwogenes ist.

Viertens lassen sich anhand von 1. Kor 8,10-11 bereits einige Beobachtungen zum komplexen Zusammenhang von Textfunktion und Gestaltung der

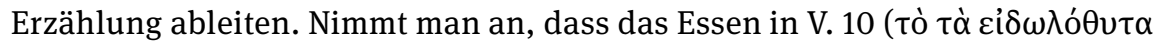

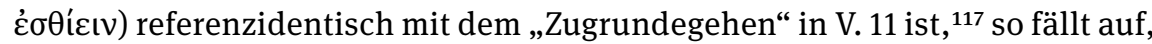
dass Paulus in den beiden - jeweils nur „potenziellen“ - Erzählungen (trotz „repetiver Narration“) unterschiedliche Terminologie wählt, wobei auch die Textfunktion verschieden zu bestimmen ist: In V. 10 muss Paulus zunächst ein Ereignis feststellen, denn aus dem Akt des Beobachtens könnten ja durchaus verschiedene Handlungsfortgänge folgen. ${ }^{118}$ In V. 11 hingegen scheint die Kommunikationsintention des Erzählers die zu sein, den zuvor ausführlicher entfalteten Geschehenszusammenhang zu bewerten. Dabei wird durch die Konnexion auf der einen Seite der inhaltliche Zusammenhang zwischen Anfangs- und Endpunkt der Ereignisfolge näher bestimmt und auf der anderen Seite durch die terminologische Variation des Resultats dieses interpretiert. Götzenopferfleisch unter besagten Umständen $\mathrm{zu}$ essen ist ein Verderbensereignis. Man könnte folglich auch sagen: In V. 11 liefert Paulus eine Interpretation der zuvor geschilderten Ereignisse (bzw. „potenziellen Erzählungen“).

117 Alternativ könnte man hier auch einen Verweis auf ein in der Zukunft liegendes Geschehen sehen, nämlich auf einen aus diesem Verhalten hervorgehenden Abfall vom Glauben bzw. eine Gerichtssituation.

118 Hier liegt ein potenzieller Anwendungsbereich des „Spielplans“ von Finnern und Rüggemeier, Methoden vor. Siehe dazu oben, Kapitel 3, Abschnitt 5.3 zum Plot. 


\subsection{Durch den Zusammenhang des Erzählten gestifteter temporaler Zusammenhang}

Bisher wurden Fälle betrachtet, in welchen die temporale Ordnung durch den von den Konnexionen selbst oft implizierten „Zeitfokus“ und durch temporal deutlichere Vertextungen desselben Sachverhaltes im unmittelbaren Kontext gestiftet wurde. Sie kann aber auch schlicht dadurch gegeben sein, dass die Relation der Ereignisse auf der Ebene des Erzählten eindeutig ist, weil aufgrund des Weltwissens der gemeinte Zusammenhang vom kooperativen Leser erschlossen werden kann.

Die Identifizierung von Ereignis-Abfolgen ist dann natürlich zu einem großen Maß von der korrekten Rekonstruktion der Referenz der paulinischen Wortwahl abhängig und oft sehr strittig. Dies gilt etwa für Röm 8,29-30:

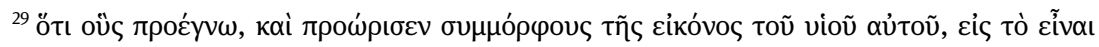

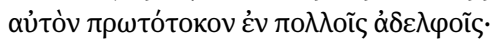

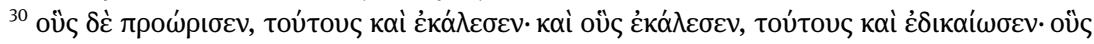

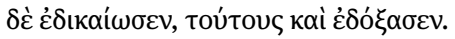

Manche Ausleger sehen hier die folgende Sequenz ausgedrückt:

1. Vorhersehung

2. Erwählung

3. Berufung

4. Rechtfertigung

5. Verherrlichung

In diesem Fall könnte man in der Reihung aus Sache-BESCHREIBUNGKonnexionen ein Mittel der vorzeitigen „überlappend-repetitiven“ Narration sehen.

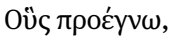

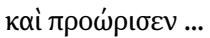

$$
\begin{aligned}
& \text { oüs } \underline{\delta \varepsilon} \pi \rho o \omega ́ \rho เ \sigma \varepsilon v,
\end{aligned}
$$

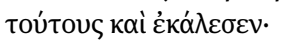

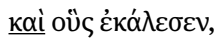

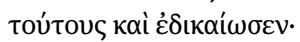

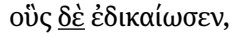

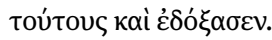

Dagegen spricht jedoch, dass $\pi \rho \circ o \rho i \zeta \omega$ in V. 29 mit doppeltem Akkusativ konstruiert ist, hier also nicht einfach nur von einem Akt des „Erwählens“ die Rede

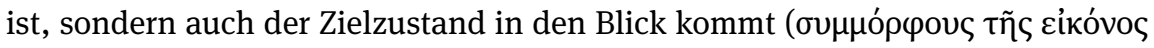

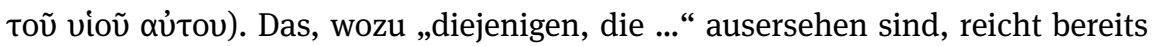


über die im Folgenden angeführten Ereignisse hinaus - bis in die Zukunft aus Sprecherperspektive, ${ }^{119}$ nämlich ,dem Bilde seines Sohnes gleichgestaltet zu werden“ (Menge). ${ }^{120}$ Es liegt also wohl keine Erzählung vor, sondern vielmehr die Beschreibung/Explikation ein und desselben Sachverhaltes. ${ }^{121}$

Wesentlich unstrittiger ist die temporale Ordnung in der Regel dann, wenn der Zusammenhang verschiedener Sachverhalte in nicht-temporalen Konnexionen durch zusätzliche Adverbien, welche eine zeitliche Relation anzeigen, näher bestimmt wird. In Kapitel 7, Abschnitt 5 wird dieser Punkt mit zahlreichen Beispielen illustriert.

\section{Sinnhafte Verknüpfung bei temporalen Konnexionen}

\subsection{Einbettung in die Makrostruktur des Propositionalgefüges}

\subsubsection{Einführung}

Temporale Verknüpfungen von Propositionen erfüllen die Narrativitäts-Bedingung der zeitlichen Ordnung sehr deutlich. Es wurde oben bereits ein Beispiel von Köppe und Kindt angeführt, welches von den Autoren bewusst ohne sinnhafte Verknüpfung gewählt wurde: ${ }^{122}$

Die Polizei fahndete nach Peter,

und an der Universität von Chicago wurden die Lehrpläne für das Wintersemester erstellt.

Selbst wenn man den Konnektor „und“ hier als Bindeglied zwischen zwei zeitlich aufeinander bezogenen, vermutlich gleichzeitigen, ${ }^{123}$ Geschehnissen auffassen würde, könnte man den Text doch nicht als Erzählung werten, weil die beiden Propositionen nicht sinnhaft verknüpft wären. Wie steht es um folgendes Beispiel?

Er verkaufte alles.

Und er kaufte die besonders kostbare Perle.

119 Vgl. Wolter, Brief I, 532.

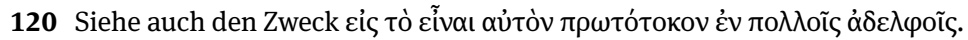

121 Wolter, Brief I, 533: „Die drei Begriffe sind nicht synonym, aber semantisch isotop, insofern sie von ein und demselben Handeln Gottes sprechen, es aber auf unterschiedliche Weise charakterisieren. Paulus beschreibt mit ihnen nicht ein zeitliches Nacheinander ..., sondern er will erklären, dass Gott schon durch sein ,Rufen' ,gerechtfertigt‘ und ,verherrlicht" hat.“

122 Vgl. Köppe und Kindt, Erzähltheorie, 55.

123 Auch eine Lesart als „und dann“ ist freilich nicht ausgeschlossen. Der betonte Ortswechsel würde bei einem kooperativen Leser aber wohl eher den Eindruck von Gleichzeitigkeit erwecken. 
In Isolation betrachtet, ist es auch hier schwierig, die Erzählhaftigkeit zu etablieren. Recht nahe liegt noch, die koordinierende Konjunktion hier als Bindeglied zwischen zwei Sequenz-Kernen aufzufassen.

Bereits das anonym bleibende Personalpronomen und die Rede von „der“ kostbaren Perle liefert einen Hinweis darauf, dass diese temporale Konnexion Teil eines umfassenderen Propositionalgefüges ist. Ein Blick auf diese höheren Ebenen der Makrostruktur des Textes (Mt 13,45-46) in Abb. 23 erlaubt nun Rückschlüsse auf die sinnhafte Verbindung, die zwischen den beiden Aussagen besteht (siehe zur hierarchischen Makrostruktur oben, Kapitel 4, Abschnitt 8). ${ }^{124}$

Wie bereits vermutet, stellen die Propositionen 5 und 7 zwei SEQUENZ-Kerne dar. Auf der nächst höheren Ebene des Propositionalgefüges geht diese zweiteilige Sequenz nun selbst wiederum eine Konnexion ein: Sie übernimmt die Rolle einer ZIEL-Proposition, welche mit einer Hinbewegung-Proposition (Proposition 4) verbunden ist.

Auf diese Weise wird zumindest bereits klar, dass zwischen den beiden Handlungen ein Zusammenhang besteht: Sie sind insofern miteinander verbunden, als von unserem Protagonisten eine Anstrengung unternommen wird, die zum Erreichen dieser beiden Ziele führen soll. Dass die beiden Ziele gemeinsam auf eine einzige Hinbewegungs-Handlung bezogen werden, legt nahe, dass auch zwischen diesen beiden Zielen ein wie auch immer gearteter gehaltvoller Zusammenhang bestehen muss.

Deutlich wird dies, weil anders als im Peter-Chicago-Beispiel hier das Agens in beiden Propositionen derselbe ist und die verschiedenen Handlungen von Erzählfiguren in der Regel durch Willensakte, welche auf ein Handlungsziel ausgerichtet sind, miteinander „,verknüpft“ sind. ${ }^{125}$ Eine kurze Erzählung wie „Ich verließ die Arbeit vorzeitig, machte als erstes den Wasserkocher an und trank dann eine Tasse Tee mit Vitamin C. “ kann leicht als Schilderung der Maßnahmen verstanden werden, die nach ersten Erkältungs-Symptomen im Büro zum Zweck der Regeneration ergriffen werden. Ein kooperativer Leser wäre wohl auch im Hinblick auf das matthäische Beispiel ohne Kontext in der Lage, das Handlungsziel und den genaueren Zusammenhang der SequenzKerne zu verstehen. Denn dass kostbare Perlen einen Preis haben, der die finanziellen Möglichkeiten vieler Menschen übersteigt, ist auch im 21. Jahrhundert nachvollziehbar.

Das Handlungsziel wird aber auf der nächsthöheren Stufe des Propositionalgefüges auch etwas expliziter gemacht: Der gesamte Handlungskomplex

124 Das Beispiel ist GGNT 312e entnommen.

125 Köppe und Kindt, Erzähltheorie, 58. 


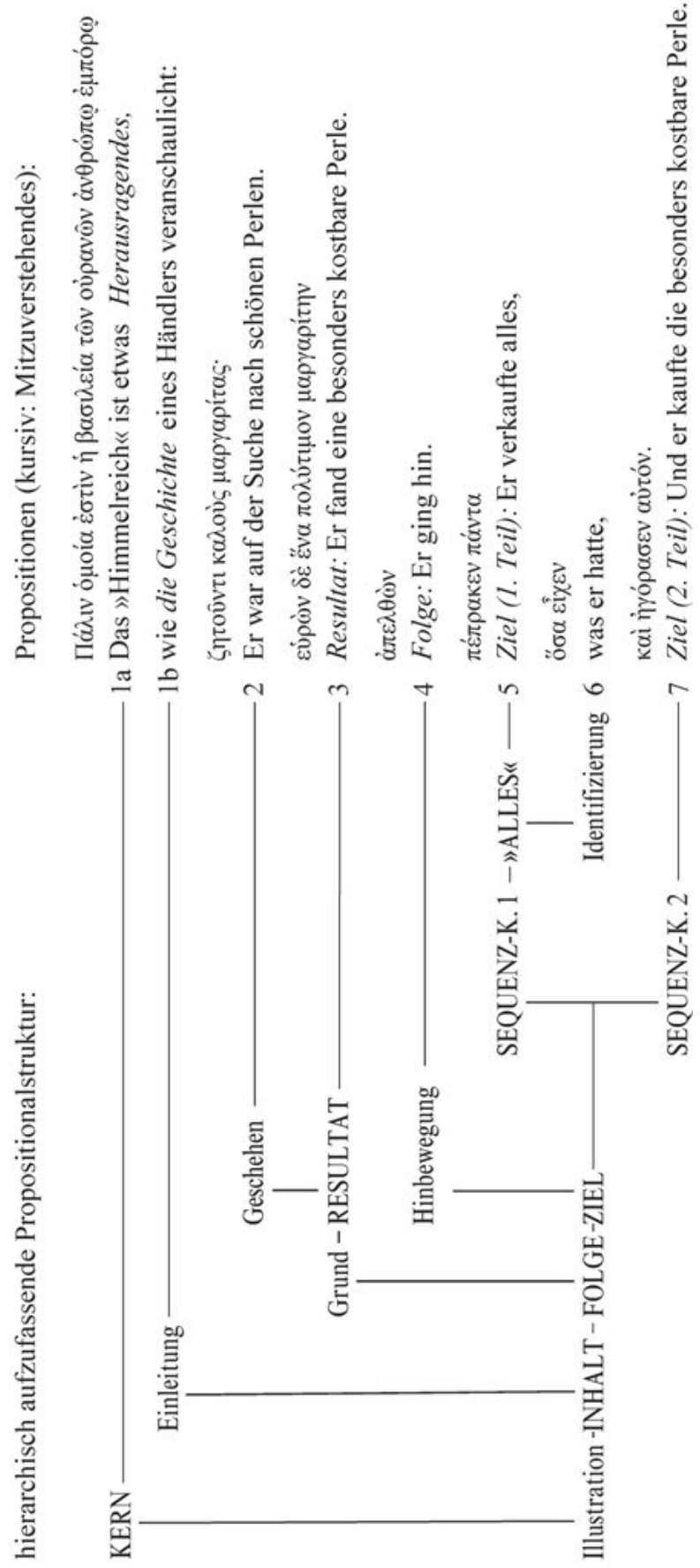

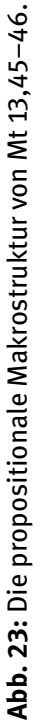


Propositionen 4-7 stellt sich als eine FOLGE eines in Propositionen 2-3 geschilderten Grundes heraus: Es ist der Fund einer besonders kostbaren Perle (Grund), der unseren Protagonisten in Bewegung setzt und zwei aufeinander folgende Handlungen durchführen lässt (Folge). Der Grund besteht wiederum selbst aus zwei Kernen, wobei der eine explizit das Handlungsziel (den Wunsch, eine schöne Perle zu besitzen) nennt und der andere einen Umstand (das Finden einer besonders schönen Perle), welcher spezifische Maßnahmen erfordert. Wie die Handlungen der temporalen Konnexion aus Proposition 5 und 7 auf dieses Handlungsziel hinwirken, ist im Text nicht im Detail festgehalten, sondern ist mitzuverstehen: ${ }^{126}$ Aufgrund des Weltwissens ist jedoch unmittelbar verständlich, dass eine besonders schöne Perle einen Wert aufweist, der nicht einfach aus dem vorhandenen Kapital der Erzählfigur heraus bezahlt werden kann. ${ }^{127}$ Die Makrostruktur des Textes stützt diese Interpretation dadurch, dass auf Suche und Finden nicht direkt der Erwerb folgt, woraus geschlossen werden kann, dass das zwischengeschaltete Handeln notwendig für den Kauf ist.

Auch wenn es der temporalen Konnexion in Isolation kaum entnommen werden könnte, stellt sich durch ihre Betrachtung im Kontext des umfangreicheren Propositionalgefüges heraus, dass durchaus eine sinnhafte Verknüpfung zwischen den beiden Sequenz-Kernen besteht: Das Verkaufen des Besitzes (Proposition 5) ist die Voraussetzung dafür, dass der Kauf der Perle (Proposition 7) abgeschlossen werden konnte.

Der Blick auf übergeordnete Ebenen des Propositionalgefüges ist somit ein wichtiges Instrument, um die Erzählhaftigkeit einer temporalen Konnexion nachzuweisen. Gerade im Kontext deutlicher und umfangreicher narrativer Vertextungen wird zwar gegenüber der Annahme, dass ein inhaltlicher Zusammenhang vorliegt, in der Regel kein Zweifel vorgebracht. Auch hier ist das skizzierte Vorgehen jedoch aus narratologischer Sicht sehr aufschlussreich, weil es hilft, den Details der Kohärenz des Erzähltextes auf die Schliche zu kommen.

126 GGNT 314. Vgl. Kapitel 4, Abschnitt 5.3.

127 Anders sähe es dementsprechend bei einem Text wie dem folgenden aus: „Bill Gates war auf der Suche nach schönen Uhren. Er sah eine besonders schöne Rolex im Schaufenster eines Händlers. Er machte sich sofort auf, verkaufte seinen ganzen Besitz und erwarb die Uhr." Hier würde der überraschte Leser sich zu einer kreativen Erklärung für die Sequenz genötigt sehen. Lediglich in bestimmten Kontexten (z. B. Erzählungen über Uhren mit magischer Wirkung, welche Sammler beim Anblick dem Wahnsinn verfallen lässt), wäre ein solcher Text problemlos verstehbar. 


\subsubsection{Illustration anhand von Gal 1,17b}

\subsubsection{Unter Einschluss von V. 16c-17a}

Dies soll kurz am vieldiskutierten Beispiel Gal 1,17b verdeutlicht werden. In Isolation betrachtet, verknüpft Paulus hier schlicht zwei Hauptsätze mit koí, wie in Abb. $24 \mathrm{zu}$ sehen ist.

\begin{tabular}{|c|c|}
\hline 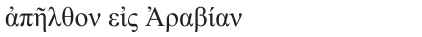 & Ich ging nach Arabien fort. \\
\hline 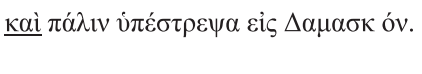 & $\begin{array}{l}\text { Und ich kehrte wieder nach Damaskus } \\
\text { zurück. }\end{array}$ \\
\hline
\end{tabular}

Abb. 24: Die koordinierende Konjunktion kaí (=,und“) in Gal 1,17b.

Da sich die Aussagen innerhalb einer deutlich erkennbaren Erzählung ereignen, wird bei der Lektüre automatisch angenommen, dass es sich hierbei um zeitlich geordnete Ereignisse handelt - obwohl formal (bis auf die Kontinuität des Agens) kaum ein Unterschied zum Peter-Chicago-Beispiel besteht. Dass an eine Sequenz und nicht an Gleichzeitigkeit gedacht ist, wird bei der Lektüre auch sofort richtig erkannt, obwohl dies der Text nicht explizit sagt. Der kooperationsbereite Leser kann sich dies jedoch bei ausreichender Geographie-Kenntnis leicht erschließen. ${ }^{128}$

Sehr umstritten ist in der Exegese jedoch das Handlungsziel, welches diesen sich aneinander anschließenden Bewegungen zugrunde liegt. Lassen sich Paulus' Bewegungen aus einem Evangelisationsbestreben heraus erklären oder sind diese „dunklen Jahre“ des Apostels als Zeit der Reflexion zu verstehen? ${ }^{129}$

$\mathrm{Da}$ zu den Grundannahmen der Kommunikation gehört, dass gemachte Äußerungen für die stattfindende Konversation relevant sind, erwarten die Leser des Galaterbriefes zurecht, dass von Paulus zumindest irgendein inhaltlichen Zusammenhang gemeint ist. ${ }^{130}$ Es ist also davon auszugehen, dass Paulus

128 Vgl. demgegenüber im unmittelbaren Kontext die mit $\delta \varepsilon \dot{~ e i n g e l e i t e t e n ~ V e r s e ~ 22-24, ~ d i e ~}$ gleichzeitig zum zuvor Geschilderten zu verstehen sind. Auch mit additivem Konnektor ist eine entsprechende Auflösung oft problemlos möglich: „Ich flog nach New York und ich aß eklige Hühnchenbrust, weil mir die vegetarische Option nicht gefiel.“ Es handelt sich hierbei natürlich um eine im Flugzeug und nicht am Zielort eingenommene Mahlzeit.

129 Eventuell dem Vorbild Elija folgend? Vgl. Wright, Pauline Perspectives, Kapitel 10 (,Paul, Arabia and Elijah [Galatians 1.17] [1996]“).

130 Dieses Relevanz-Kriterium ist im Übrigen auch im Beispiel von Köppe und Kindt einer NichtErzählung erfüllt, denn die Willkürlichkeit ist ja explizit Teil des Äußerungskontextes: Was das Beispiel von Köppe und Kindt als Erzählung disqualifiziert, ist genau der Umstand, dass die Au- 
in Gal 1,17b zwei Bewegungen benennt, die über eine gleichbleibende oder sich zumindest kontinuierlich entwickelnde Intention verbunden sind. Bei der Frage danach, worin das Handlungsziel besteht, liefert eine Analyse der Integration der temporalen Konnexion in die umfassendere Makrostruktur, aller Uneinigkeit in der Exegese zum Trotz, ${ }^{131}$ recht deutliche Hinweise.

Als erstes ist festzustellen, dass durch $\alpha \lambda \lambda \alpha \dot{\alpha}$ eine adversative Konnexion nach dem Muster Negativum-POSITIVUM zwischen der besagten Sequenz auf der einen Seite und V. 16c-17a auf der anderen Seite markiert wird. ${ }^{132}$ Die Sequenz aus $1,17 \mathrm{~b}$ wird also als in einem Gegensatz zu einem verneinten Sachverhalt im vorausgehenden Text dargestellt.

Dieser den Gegensatz bildende, verneinte Sachverhalt wiederum wird durch zwei additiv verbundene Propositionen entfaltet. Abb. 25 gibt einen Überblick über die so gebildete Struktur. ${ }^{133}$

\begin{tabular}{|c|c|c|}
\hline \multirow{2}{*}{ Negativum } & ADDITIV -KERN 1 & 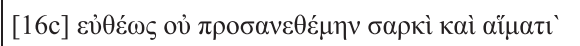 \\
\hline & ADDITIV -KERN 2 & 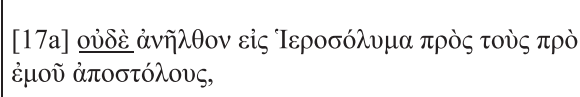 \\
\hline \multirow{2}{*}{ POSITIVUM } & SEQUENZ -KERN 1 & 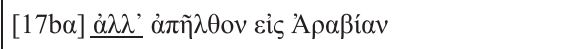 \\
\hline & SEQUENZ -KERN 2 & 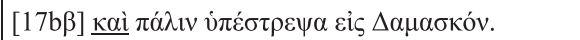 \\
\hline
\end{tabular}

Abb. 25: Die Propositionalstruktur von Gal 1,16c-17b.

Was kann für V. 17b nun aufgrund der übergeordneten Ebenen in der Propositionalstruktur geschlussfolgert werden? In der Regel ${ }^{134}$ wird durch den addi-

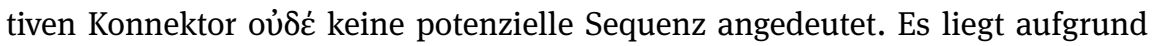
der getroffenen erzählerischen Entscheidungen also zumindest nicht nahe, das

toren (Köppe und Kindt, Erzähltheorie, 56) „die Ereignisse ja gezielt wahllos aneinandergereiht [haben], ohne eine sinnhafte Verknüpfung zu verstehen geben zu wollen.“

131 Teilweise ist diese aus einer einzelne Phänomene des Textes als Ausgangspunkt nehmenden „abduktiven“ Formulierung neuer Hypothesen zu verstehen (so bei Wright, „Paul, Arabia, and Elijah"). Grundsätzlich ist hiergegen auch nichts einzuwenden, sofern sich dann auch eine entsprechende Evaluation der Interpretation unter Berücksichtigung des Kontextes anschließt. Vgl. grundsätzlich Heilig und Heilig, „Historical Methodology.“

132 Vgl. GGNT 338a.

133 Vgl. GGNT 325c.

134 Siehe unten, Kapitel 10, Abschnitt 3.4 für den Vorschlag einer Ausnahme. 
Negativum-Element ebenfalls als Sequenz zu lesen, also als Verneinung einer Handlungsfolge $\mathrm{zu}$ verstehen, in welcher auf einen Gang nach Jerusalem eine Konsultation von Fleisch und Blut gefolgt wäre.

Noch weniger plausibel ist eine in der Exegese nicht selten anzutreffende explizierende Stoßrichtung, wobei also angenommen wird, dass der Besuch in Jerusalem der größeren Kategorie der Konsultation von Fleisch und Blut zuzuordnen wäre. ${ }^{135}$ Paulus stellt dem POSITIVUM-Element also nicht nur ein einzelnes, durch eine zweite Proposition erläutertes Geschehen gegenüber.

Gemeint sind also wohl, der Standardfunktion des Konnektors entsprechend, ${ }^{136}$ schlicht zwei Handlungsmöglichkeiten, die sich Paulus zum besagten Zeitpunkt boten, von ihm aber nicht wahrgenommen wurden. Es ist dabei aufgrund der einzufordernden kommunikativen Relevanz davon auszugehen, dass diese beiden Alternativen nicht willkürliche Optionen listen, sondern als gemeinsamen Nenner plausible Möglichkeiten im Rahmen einer bestimmten Absicht darstellen. ${ }^{137}$

Sucht man nach einem konkreten Paar solcher Optionen, ergibt sich für „Blut und Fleisch“ (eigentlich nur) eine naheliegende Referenz: Paulus betont, er habe sich weder mit Autoritäten in seinem direkten Umfeld beraten (was ein naheliegender nächster Schritt gewesen wäre) noch den Weg auf sich genommen, um die Jerusalemer Apostel zu befragen (was eine andere Möglichkeit gewesen wäre, dem Ziel des Ratsuchens nachzukommen).

Wie lässt sich ein solches Verständnis des Negativum-Kerns auf einer höheren Ebene der Propositionalstruktur integrieren? Die Verbindung der beiden additiven Kerne mit den beiden temporalen Kernen durch $\alpha \lambda \lambda \alpha \dot{\alpha}$ impliziert, dass das positiv Ausgesagte in einem Gegensatz zu der Intention steht, welche den beiden additiven Kernen zugrunde gelegen hätte. Die Berücksichtigung der propositionalen Makrostruktur des Textes zeigt also, dass die Propositionen der temporalen Konnexion in Gal 1,17b sinnhaft dadurch verknüpft sind, dass beide Handlungen eigenständige Reisebewegungen darstellen. Es ist daher gar nicht nötig, im Detail ein Handlungsmotiv zu finden, das sowohl die Bewegung nach Arabien als auch „zurück“ nach Damaskus erklären würde. ${ }^{138}$ Der „gemeinsame Nenner“ besteht darin, dass Paulus hier aktiv ist - ohne eine der beiden im

135 Gegen Moo, Galatians, 106, der meint: „Paul elaborat[es] ,flesh and blood“ in terms of ,the apostles who were before me.““

136 GGNT 325c.

137 Vgl. etwa: „Als Du mich anriefst, habe ich dich weder weggedrückt noch auf lautlos gestellt, sondern bin sofort rangegangen.“

138 Anders als z. B. in: „Ich suchte auf dem Schreibtisch und ich suchte nochmal im Auto - aber meinen Schlüssel fand ich einfach nicht.“ 
Negativum-Kern spezifizierten und einander sehr ähnlichen Optionen wahrgenommen $\mathrm{zu}$ haben.

Dieses Verständnis der sinnhaften Verknüpfung innerhalb der temporalen Konnexion von Gal 1,17b ist selbstverständlich von der hier angenommenen Referenz von „Fleisch und Blut“ abhängig. Die hier vorgeschlagene Interpretation folgt keinesfalls zwingend aus der Formulierung. Geht man jedoch davon aus, dass es im Rahmen der Kommunikation ein sinnvolles Verständnis geben muss, ist dieses Verständnis sicherlich das nächstliegende. Zudem lässt es sich aber auch noch unabhängig bestätigen, indem auch die noch weiter übergeordneten Ebenen der Propositionalstruktur berücksichtigt werden, wie im Folgenden kurz skizziert werden soll.

\subsubsection{Unter Einschluss von V. 15-16b und 13-14}

Wie Abb. 26 zeigt, stellen die Verse 15-16b als Ganzes lediglich ${ }^{139}$ einen durch ö $\tau \varepsilon$ eingeleiteten Zeithinweis zum bisher besprochenen Komplex 16c-17 dar.

\begin{tabular}{|c|c|}
\hline Zeithinweis & 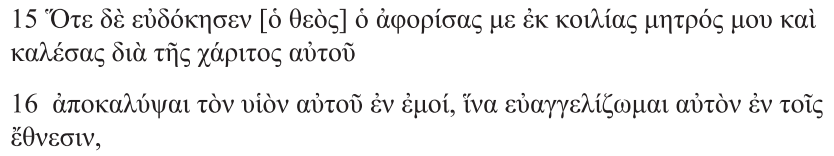 \\
\hline KERN & 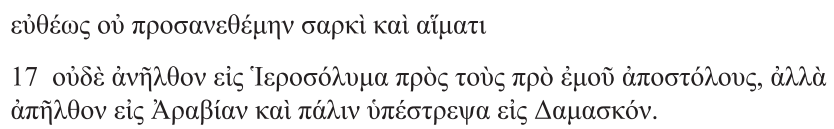 \\
\hline
\end{tabular}

Abb. 26: Die propositionale Rahmenstruktur von Gal 1,15-16.

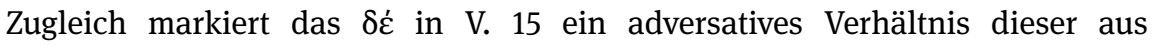
15-16b auf der einen Seite und 16c-17 auf der anderen Seite bestehenden Zeithinweis-KERN-Konnexion gegenüber dem im Text Vorangehenden. ${ }^{140}$ V. 15-17 als Ganzes bilden also ein KERN-Element, für welches zuvor ein KontrastProposition geliefert wird.

139 Diese Formulierung nimmt darauf Bezug, dass in der Exegese häufig die hierarchische Struktur des Propositionalgefüges nicht ausreichend berücksichtigt wird. Im Laufe der Diskussion dieser Passage wird aber auch auf die Möglichkeit verwiesen, dass textexterne Faktoren eine Interpretation im Sinn einer „Berufungsgeschichte“ dennoch möglich machen könnten.

140 Der Konnektor $\delta \varepsilon ́$ ist mit dem Hauptsatz zu verbinden. Siehe oben, Kapitel 4, Abschnitt 6. 
Dass Paulus zu einem bestimmten Zeitpunkt also etwas (eine Sequenz) unternahm, was einem anderen möglichen Vorgehen (zwei genannten Optionen) widersprach, steht folglich in einem Widerspruch zu V. 13-14. Der Blick auf die Makrostruktur des Propositionalgefüges, in welches die temporale Konnexion 17b eingebunden ist, lenkt somit den Blick auf die vorangehende Binnenerzählung (,ihr habt gehört ...“). ${ }^{141}$

Ist diese Auflösung der Textstruktur korrekt, sollte das paulinische Handeln in 17b bzw. das Unterlassen der Handlungen von 16c-17a demnach als vom Muster in 13-14 deutlich divergierend verstehbar sein.

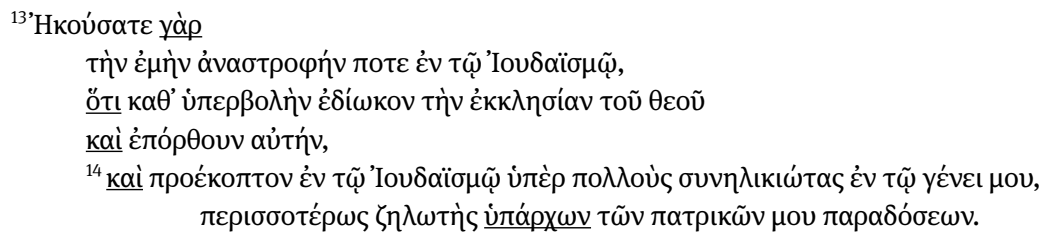

Die Äußerungsbedeutung ließe sich in etwa wie folgt wiedergeben:

Denn ihr kennt die Geschichte, wie ich mich in meinem früheren Leben im Judentum verhalten habe, dass ich die Gemeinde aufs Ärgste verfolgt und sie zu zerstören versucht habe und (dass) ${ }^{142}$ ich im Judentum mehr Fortschritte machte als viele Gleichaltrige in meinem Volk, wobei ich einen größeren Eifer an den Tag legte für die Überlieferungen meiner Vorfahren.

Um den Kontrast des Komplexes V. 15-17 zu diesem Textteil herausarbeiten zu können, ist folglich zunächst eine Interpretation der Binnenerzählung in

141 Siehe oben, Abschnitt 3.6.

142 Diese Übersetzung trägt dem Umstand Rechnung, dass in der Übersicht der Konnektor кó zu Beginn von V. 14 auf dieselbe syntaktische Ebene eingerückt ist wie die drei InhaltsPropositionen, die in V. 13 auf die Einleitung der Binnenerzählung folgen. Es wird also davon ausgegangen, dass das ö ı zunächst die Erzählung von der Verfolgung einleitet und mit dieser Proposition zwei weitere Ereignisschilderungen abhängig sind. Löst man die Syntax so auf, bilden die Verse 13-14 als Ganzes einen Einleitung-INHALT-Komplex, welcher die Kontrastfolie für das im Folgenden Entfaltete bietet.

Alternativ könnte man auch erwägen, dass die Binnenerzählung lediglich Vers 13 beinhaltet. V. 14 wäre dann nicht mehr Teil des Gehörten, sondern eine unabhängige, im Brief selbst eventuell erstmals gebotene Erzählung, eine Zusatzinformation zu dem, was die Galater über Paulus bereits erfahren hatten. Das einleitende koí wäre dann entsprechend auch eine Ebene nach außen zu rücken (zum yó $\rho$ ). Geht man davon aus, dass V. 14 einen Neuansatz bildet, so hieße dies für den von uns gesuchten Kontrast zum KERN V. 15-17, dass dieser entweder in V. 14 alleine zu finden sein müsste oder aber V. 13 und V. 14 zwar den Kontrast liefern, selbst jedoch zuvor noch eine noch näher zu bestimmende Konnexion eingehen. 
V. 13-14 notwendig. Hierfür bieten sich ganz grundsätzlich zwei Optionen an. Die Möglichkeit dieser alternativer Vorgehensweisen hängt mit der Existenz zweier unterschiedlicher, wechselseitig interagierender Strategien im Prozess des Verstehens zusammen:

(1) Es ist möglich, das Gemeinte von der Textfolge her zu erschließen. Dem Leser begegnet zunächst V. 13-14. Dass die beiden Verse auf einer höheren Ebene der Makrostruktur des Propositionalgefüges anzusiedeln sind als einige noch folgende Aussagen, kann der Leser noch nicht wissen. Er kann somit noch nicht auf untergeordnete Ebenen des Gefüges zugreifen, welche Spezifikationen des Gemeinten bieten könnten. Der Leser steht vor der Frage: Worum geht es? Was ist das „Thema“ dieser Erzählung? Diese Erschließung des Themas erfordert Interpretationsleistung und kann zunächst in verschiedene Richtungen gehen. Viele Exegeten gehen hierbei von der Beobachtung aus, dass die einzelnen Elemente der Erzählung inhaltlich einen gemeinsamen Nenner aufzuweisen scheinen - die feindliche Einstellung gegenüber der christlichen Gemeinde. Durch die Rede vom „zelotischen“ Eifer in V. 14 scheint auch dieses Element gut mit einer solchen Interpretation vereinbar. Es würde sich daher anbieten, den Kontrast zu dem, was im Text folgt, als auf diesen Faktor bezogen zu sehen. Für die Negativum-POSITIVUM-Relation in V. 16c-17 würden sich dann folgende Implikationen ergeben:

(a) Das positiv Ausgesagte in V. 17b ist dadurch charakterisiert, dass es sich hierbei um Bewegungen im Interesse des christlichen Glaubens handelt. Damit wäre dann freilich auch geklärt, was Paulus in Arabien getrieben hat - es müsste sich um Missionsarbeit gehandelt haben!

(b) Die additiven Kerne der negativen Kehrseite (V. 16c-17a) müssten so aufgefasst werden, dass sie ein sinnvolles Gegenstück zu dieser Aktivität darstellen könnten. Man könnte etwa argumentieren, dass die Konsultation lokaler und weiter entfernter Autoritäten unnötig das Engagement für die Verkündigung hinausgezögert hätte. Eine weitere Möglichkeit wäre, in den Verweisen auf Fleisch/Blut und die Apostel in den beiden additiven Kernen Verweise auf Größen zu sehen, die für Paulus noch der Sphäre des alten Lebenswandels, wie er in V. 13-14 beschrieben wurde, zuzuordnen wären. Beide Lesestrategien müssen sich letztlich im Rahmen der Lektüre des Briefganzen bewähren und sind in dieser Hinsicht jeweils nicht ohne Probleme. So ist im ersten Fall zumindest verwunderlich, dass Paulus seine Reisebewegungen in $17 \mathrm{~b}$ nicht spezifischer mit einem Handlungsmotiv versieht. Im zweiten Fall scheint vor allem die spätere Schilderung der Interaktion mit Jerusalem - trotz aller 


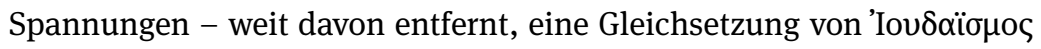

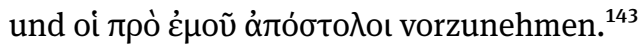

(2) Bei einer Lektüre in Textfolge ergeben sich also aufgrund dieser späteren Aussagen begründete Zweifel am geschilderten Verständnis der Binnenerzählung. Sie muss zwar zwangsläufig zunächst in Isolation interpretiert werden, diese Interpretation muss sich dann aber auch im Rahmen der Makrostruktur des Textes, welche sich erst nach und nach entfaltet, bewähren. Es liegt daher nahe, umgekehrt - vom untergeordneten Teilgefüge V. 16c-17 her - den Beitrag von V. 13-14 auf einer höheren Textebene zu erschließen.

Dann aber drängt sich der Aspekt der in dieser Erzählung enthaltenen Orientierung an menschlichen Autoritäten sehr deutlich auf: Die in V. 13c-d geschilderte Feindseligkeit gegenüber den Christen erscheint nun eher als Hintergrund zu dienen für das in V. 14 Geschilderte, beziehungsweise als „Datierungshilfe.“ Paulus möchte einen Aspekt seines früheren Lebens kommunizieren und greift zu diesem Zweck zunächst die über ihn kursierenden Kenntnisse auf. Wie auch immer die Binnenerzählung V. 13-14 in ihrem ursprünglichen Kontext gelautet haben mag, zumindest im gegenwärtigen Briefkontext wäre für die Kommunikationsintention des Paulus nicht so sehr die Verfolgung der Gemeinde Gottes, sondern die zur damaligen Zeit noch starke Ausrichtung an menschlichen Bezugspunkten zentral. Dieses Verständnis der Erzählung bestätigt sich vor allem dadurch, dass diese Einbettung in ein soziales Netzwerk sehr ausführlich dargelegt wird: das Vor-

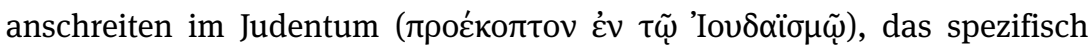

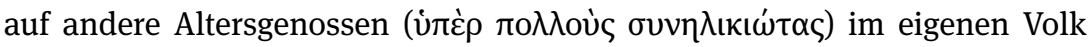

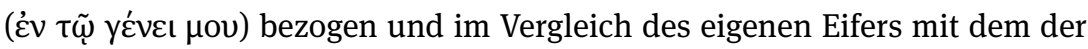

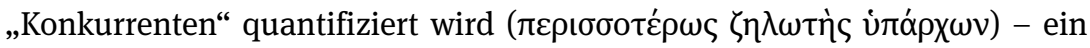

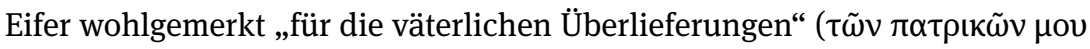

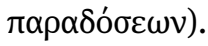

Bei der Erstlektüre in Textfolge können diese Elemente nur schwer in das oben skizzierte „Thema“ integriert werden. Denn, dass V. 14 etwas mit „Christenverfolgung “ zu tun hat, liegt eigentlich nicht nahe. Bei einer entsprechenden Erstlektüre (bzw. Lektüre unter analoger Voraussetzung) werden diese Elemente daher eventuell schlicht zugunsten der leichter zugänglichen Aussagen in V. 13 in ihrer Signifikanz für die Interpretation herabgestuft. Ein solches Vorgehen ist auch grundsätzlich nicht unangebracht (im Zuge der Textrezeption begegnen immer - zumindest

143 Eine Diskussion des Verhältnisses zwischen Paulus und Jerusalem wird an anderer Stelle (Heilig, „New Perspective“ und Heilig, „Petrus-Traditionen“) geboten. 
zunächst - unklare Elemente), sofern die so gewonnene Interpretation als provisorisch erkannt wird.

Der Leser kann freilich auch direkt zur plausibleren Interpretation der Binnenerzählung V. 13-14 vordringen, wenn er sich vom Konnektor yó $\rho$ in V. 13 angemessen leiten lässt und ein Propositionalgefüge erwartet, das als Ganzes zur Untermauerung des wiederum zuvor bereits in V. 9-12 Gelesenen beiträgt. Es wird unten (Kapitel 8, Abschnitt 5.4) noch im Detail gezeigt werden, wie sich der ab V. 13 beginnende Abschnitt selbst wiederum auf höherer Ebene in das Propositionalgefüge einfügt.

Spätestens mit V. 16c-17 drängt sich jedoch eine eventuell notwendige Revision des Verständnisses der Binnenerzählung V. 13-14 auf. ${ }^{144}$ Gleichzeitig bestätigt die so gewonnene präzisere Interpretation von V.13-14 und die entsprechende Bestimmung des Themas auch die oben vor dem Hintergrund von V. 16c-17a (der Negativum-Komponente zum POSITIVUM V. 17b) bereits angestellten Überlegungen zur Relevanz der Narration der paulinischen Bewegungen nach Arabien und zurück nach Damaskus.

V. 13-14 bestätigt jedoch nicht nur die bei der isolierten Betrachtung von V. 16c-17 angestellten Überlegungen. Die Makrostruktur des Propositionalgefüges liefert auch eine Erklärung der Relevanz der erzählten eigenständigen Reisebewegungen für den größeren Erzählzusammenhang. Es ist vor diesem Hintergrund, dass nicht nur der sinnhafte Zusammenhang der Sequenz in V. 17b, sondern auch der „Witz“145 der Reise nach Arabien und zurück deutlich wird: Der Leser darf aufgrund der Binnenerzählung durchaus erwarten, dass der so charakterisierte damalige - an anderen Menschen orientierte - Paulus in einer außergewöhnlichen Situation zunächst den Rat anerkannter Autoritäten suchen würde. Der Kontrast zwischen V. 13-14 und dem KERN V. 15-17 besteht also nicht so sehr im religiösen Systemwechsel (denn dann hätte Paulus einfach andere Autoritäten aufsuchen können) - sondern in der mit diesem Wechsel einhergehenden grundsätzlichen Neuausrichtung der das eigene Verhalten bestimmenden Faktoren.

\footnotetext{
144 Angesichts des sich immer rasanter entwickelnden Marktes für biblische Kommentare gerade im englischsprachigen Raum - ist es nicht weiter verwunderlich, dass zuweilen Interpretationen kaum von solcher „Erstlektüre“ zu unterscheiden sind: die Zusage der Fertigstellung des Manuskriptes erlaubt im Grunde kaum mehr als eine spontane Kommentierung in Textfolge. Umfassende Revisionsprozesse aufgrund sich erst später - auf einer tiefer gelegenen Ebenen des Propositionalgefüges - zeigenden Lektürehinweisen können dann kaum noch integriert werden, da grundsätzliche Entscheidungen zum „Thema“ bereits getroffen sind. Siehe unten, Fazit, Abschnitt 16 zur Situation der gegenwärtigen Kommentarliteratur in der neutestamentlichen Wissenschaft.
}

145 Siehe oben, Kapitel 3, Abschnitt 3.4.4.4. 
Das Beispiel Gal 1,17b zeigt also eindrucksvoll, dass sich die sinnhafte Verknüpfung einer temporalen Konnexion oft auf einer höheren Textebene erschließen lässt - wobei im Zuge der Deutung nicht selten zwischen individuellen Propositionspaaren und größeren Einheiten des Text(teil)s hin und her gewechselt werden muss.

Die wechselseitige Interaktion von „bottom-up“- und „top-down“-Prozessen $^{146}$ im Zuge des das Verstehen als Ziel habenden „Parsings“ 147 hilft natürlich nicht nur bei der Ermittlung der sinnhaften Verbindung zweier Propositionen einer temporalen Konnexion. Es kommt immer zu diesem Wechselspiel, wenn die Propositionalstruktur eines Textes erschlossen werden soll: Die Makrostruktur des Textes ergibt sich aus dem Verständnis einzelner Propositionspaare, während die Deutung der einzelnen Konnexionen wiederum beeinflusst ist von einem Vorverständnis der Gesamtstruktur des Textes (wobei bei der Erstlektüre dieses natürlich noch eine kleinere Basis hat).

\subsection{Temporale Konnexion auf der äußersten Ebene des Propositionalgefüges}

\subsubsection{Darstellung des Problems}

Der Rückgriff auf nicht-temporale Konnexionen auf übergeordneten Textebenen ist jedoch nicht immer ein gangbarer Weg. Denn es ist durchaus möglich, dass auf der äußersten Ebene der Propositionalstruktur lediglich eine chronologische Konnexion vorliegt, aus narratologischer Perspektive also lediglich der Aspekt der temporalen Ordnung sprachlich ausgedrückt wird.

Oft ist nicht einmal eindeutig zu klären, $o b$ ein temporaler Fortschritt tatsächlich einen narrativen Neuansatz bildet oder ob er nicht doch eher noch als Teil einer vorausgehenden untergeordneten sinnhaft eingeordneten Einheit zu verstehen ist. Dieses Problem stellt sich beispielsweise direkt in Gal 1,18, wo mit

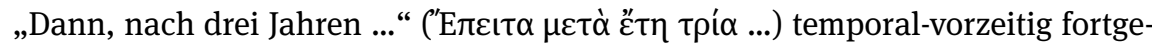
fahren wird. Lediglich die ausführliche Ausgestaltung im Anschluss legt nahe, dass die so eingeleitete Proposition nicht mehr Teil des POSITIVUM-Elements aus V. 17b ist.

Das Problem, dass für temporale Konnexionen auf höherer Ebene des Propositionalgefüges keine nicht-temporalen Konnektoren vorliegen, welche den gemeinten sinnhaften Zusammenhang verdeutlichen, begegnet insbesondere bei

146 Vgl. GGNT 310.

147 Vgl. GGNT 311a. 
größeren Texteinheiten und noch einmal in verstärktem Maß, wenn die narrative Vertextung zwischenzeitlich unterbrochen wird.

So weisen Gal 1,18, 1,21 und 2,1 jeweils हैं $\varepsilon ı \tau \alpha$ als temporal-vorzeitigen Konnektor auf. Unterbrochen wird die Sequenz in 1,20 durch einen meta-narrativen Kommentar des Erzählers, der die Wahrhaftigkeit seiner Schilderung beteuert und durch einen Wechsel der Perspektive in 1,22-24, wo ein mit 1,21 gleichzeitiger, aber an einem anderen Ort stattfindender Handlungsstrang thematisiert wird.

In der exegetischen Literatur wird viel darüber diskutiert, wie die drei konkreten Zeitangaben zu verstehen sind (ob sie aufeinander aufbauen oder vielmehr einen gemeinsamen Bezugspunkt haben, von dem aus gezählt wird). Wesentlich problematischer für das Verständnis scheint aber der nur durch die textgrammatische Analyse ersichtliche Umstand (siehe Abb. 52), dass diese drei temporalen Sequenz-Blöcke auf einer höheren Ebene nicht durch nicht-temporale Konnektoren verbunden sind. ${ }^{148}$

Die vom Leser an solchen Stellen angenommenen sinnhaften Verknüpfungen zwischen den temporalen Konnexionen hängen daher unauflösbar mit dem Gesamtverständnis der Erzählung zusammen. Ein Erschließen der sinnhaften Relationen erfordert somit umfassende interpretatorische Entscheidungen und ist nicht zuletzt abhängig vom angenommenen außertextlichen Kontext des Erzählaktes.

\subsubsection{Textstruktur und Interpretation: Zu Plot und Thema von Gal 1,13-17}

An dieser Stelle bietet sich eine kurze Betrachtung des Konzepts des Plots an, wie es oben (Kapitel 3, Abschnitt 5.3) bereits als, die chronologische Abfolge und sinnhafte Verknüpfung der zentralen Ereignisse eines Erzählwerkes‘ eingeführt wurde. Diese Definition lässt sich nicht nur auf Erzählwerke, sondern auch auf komplexere narrative Vertextungen innerhalb der Paulusbriefe, wie etwa Gal 1,13-2,21, anwenden. Wie oben (Kapitel 3, Abschnitt 6 und Kapitel 4, Abschnitt 9) bereits angedeutet, liefert die textgrammatische Analyse zwar eine Methode im Rahmen einer intentionalistischen Interpretationstheorie, kann jedoch nicht sämtliche die Bedeutung betreffenden Fragen objektiv klären. Gerade an Gal 1,13-17 zeigt sich sowohl der Wert der textgrammatischen Methode - insofern sich hier verschiedene Interpretationen, die sich auf dieselben Voraussetzungen

148 Siehe auch Rogers, Galatians, 31 für das Gemeinte, wobei seine Analyse von Gal 1,13-24 dahingehend zu kritisieren ist, dass er 1,16c als Beginn eines erstes Sequenz-Blocks betrachtet. Das

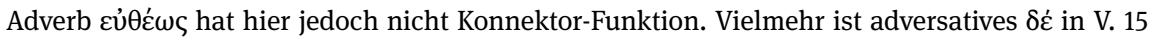
Konnektor des Hauptsatzes V. 16c. 
berufen, als unterschiedlich plausibel erweisen - als auch die grundsätzliche Abhängigkeit der Interpretation von textexternen Faktoren, selbst wenn Einigkeit über Bedeutungskonzeption und Methodik besteht.

Die textgrammatische Analyse von Gal 1,13-17 zeigt, dass V. 15-16b im Rahmen des umfassenderen Propositionalgefüges lediglich einen Zeithinweis zu einem übergeordneten Kern darstellt. Die Sequenz in V. 16c-17 geht im Rahmen einer Negativum-POSITIVUM-Konnexion einen Kontrast mit der Binnenerzählung V. 13-14 ein und nicht mit den in V. 15-16b festgehaltenen Ereignissen. Diese Beobachtungen erlaubten recht weitgehende Schlussfolgerungen in Bezug auf den „Witz“ der in V. 16c-17 erwähnten unterlassenen und unternommenen Handlungen, also unter anderem auch Antworten auf die Frage, weshalb Paulus ausgerechnet die beiden Bewegungen nach Arabien und zurück nach Damaskus aus seiner Lebensgeschichte auswählt und temporal verknüpft in einer auch isoliert als Miniaturerzählung erkennbaren Vertextung in V. 17b darstellt.

Die Resultate der textgrammatischen Analyse regen folglich zu einer Interpretation des Abschnitts Gal 1,13-17 an, deren Thema man wohl primär weder als „Bekehrungs-“ noch „Berufungserzählung“ (die beiden in der Regel diskutierten Optionen) charakterisieren würde. Ausgeschlossen ist eine solche Interpretation der Erzählung damit natürlich nicht: Die Aussage, dass es sich bei der Rede vom Entschluss Gottes, Paulus zu berufen, (wie bisher formuliert wurde) „lediglich“ um einen Zeithinweis liefert, bezieht sich auf die Propositionalstruktur des Textes. Um ein „marginales“ Ereignis im Sinne der Plot-Analyse handelt es sich dabei sicherlich nicht. Dass Paulus ein solch wichtiges Element der erzählten Welt hier nur am Rande streift, erklärt sich wohl aus der Pragmatik des Textes: Den Galatern ist dieses Ereignis längst bekannt und seine ursprüngliche Schilderung blieb sicherlich nicht ohne Rückfragen und Erklärungen. Im Rahmen der spezifischen Intention der hier gebotenen Narration, Bewertungen zweier Lebensabschnitte vorzunehmen, kann das Geschehen daher sprachlich sehr prägnant aufgegriffen werden.

Letztlich hängt es aber von der grundsätzlichen „Verständnisweise,“149 mit welcher man dem Text als Leser begegnet, ab, wie man die Handlung der Erzählung aus den geschilderten Ereignissen bildet. So ließe sich sicherlich auch ein anderer historischer Kommunikationskontext entwerfen, in welchem die Reduktion des Erzählens des Offenbarungsereignisses einen ganz anderen pragmatischen Effekt haben könnte (z.B. die Erschaffung einer bewusst „mysteriös“ erscheinenden Berufungserzählung). 
Dann könnte unter Umständen das Thema der Erzählung in der Tat in einer Proposition gebündelt gesehen werden, welche im Rahmen des Propositionalgefüges auf einer tiefen Ebene „verborgen“ ist. Freilich müssen diese Vorannahmen zum historischen Kontext (dies gilt auch für angenommene zirkulierende Erzählungen durch die Gegner) selbst plausibilisiert werden. Völlig unabhängig davon besteht natürlich auch die Möglichkeit, den Text (anachronistisch) „als Berufungs-/Bekehrungsgeschichte“ zu lesen, wenn die gewählte Interpretationstheorie eine solche Lektüre zulässt.

Die gemeinte Bandbreite der möglichen interpretativen Verfahren - ebenso wie die Notwendigkeit, das jeweils gewählte Vorgehen klar zu benennen, sodass es einer Evaluierung zugänglich wird - lässt sich gut an der neuen Arbeit zum Konzept der ,Gnade‘ bei Paulus, die von von John M. G. Barclay vorgelegt wurde, illustrieren. ${ }^{150}$

Bevor er sich der Exegese des Galaterbriefes zuwendet, diskutiert er verschiedene paradigmatische Verständnisweisen (,readings“) des Briefes, ${ }^{151}$ die allesamt verschiedene im Brief zur Sprache kommende Dualitäten (z. B. Glaube an/ von Christus vs. Werke des Gesetzes) in das thematische Zentrum stellen. Barclay selbst kündigt dann an, den Brief unter der Annahme auszulegen, dass für Paulus die Erfahrung des „Christus-Geschenks“ (als ein ohne Berücksichtigung des Wertes des Empfängers gegebenes Geschenk) das thematische Zentrum des Briefes darstellte. ${ }^{152}$ Entsprechend überschreibt er die Auslegung von Gal 1,13-24 mit: „Paul's Call as the Drama of an Incongruous Gift.“"153 Im Vergleich zur oben vor dem Hintergrund der textgrammatischen Analyse von Gal 1,13-17 gebotenen Interpretation fallen manche Schwerpunktsetzungen Barclays besonders auf, die hier kurz zusammengefasst werden sollen.

Ganz grundlegend fällt auf, dass Barclay großen Wert auf die Verse 15-16 als ein „event that bore no relation to the worth of his Jewish identity or to his former conduct ,in Judaism““ legt. ${ }^{154}$ Entsprechend wird der Binnenerzählung V. 13-14 der Sinn zugesprochen, zu verdeutlichen, dass die jüdische Lebensweise des Paulus ihn nicht für den Ruf Gottes qualifizierte, „his conduct ,in Judaism“ set him directly against, not for, God. "155 Dadurch werde verdeutlich, dass die dann geschilderte Berufung keinen weiteren Fortschritt im Eifer bedeutete. Umgekehrt werde vielmehr klar, dass die „established standards of value, according to which

150 Barclay, Gift.

151 Barclay, Gift, 339-350.

152 Barclay, Gift, 350.

153 Barclay, Gift, 356.

154 Barclay, Gift, 358.

155 Barclay, Gift, 357. 
Paul surpassed his contemporaries“ gerade zur Verfolgung der Gemeinde Gottes führten und somit bei der gnadenvollen Zuwendung Gottes eben keine Rolle spielten. ${ }^{156}$

Barclay misst in Übereinstimmung mit dieser grundsätzlichen Lesart den einzelnen Aussagen und Termini (v. a. xópıৎ in V. 15) in diesem Abschnitt große Bedeutung zu und sagt etwa: ${ }^{157}$

Paul is particularly interested in what God says or does before the birth of a person, because this circumvents definitions of worth given by birth or accumulated thereafter.

Die Erzählung handelt demnach in Barclays Sicht vor allem von der „incongruity of God's intervention“ im Leben des Paulus. ${ }^{158}$ Der Fokus der Lektüre Barclays liegt dabei gerade auf der Wandlung in V. 16ab (die dort nicht indikativisch erzählt wird):

His transformation was neither occasioned by his own action nor conditioned by his previous worth; it resulted from the unconditioned gift of God-in-Christ.

Diese Plot-Analyse und das damit verbundene Verständnis des Themas als „incongruent grace“ geht schließlich mit einer Setzung der Klimax einher, im Lichte derer der Text ab Gal 1,16c, trotz des Hauptsatzes, eher als Anhang erscheinen muss: „The years following Paul's call are sketched in the barest of outlines." "159 Die ausführlich vertextete unterlassene Konsultation menschlicher Autoritäten ist dementsprechend lediglich eine sekundäre Implikation der Gnaden-Erfahrung: „Because his message was unaligned to human norms (oủ

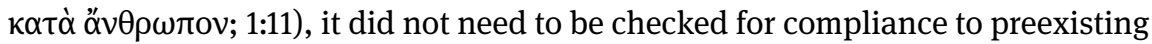
criteria." ${ }^{160}$ Die Apostel in Jerusalem scheinen dabei als spezielle Ausprägung von „Fleisch und Blut“ angeführt worden zu sein. ${ }^{161}$

Man kann die Briefe des Paulus natürlich auch auf ihren Ertrag zur Thematik der ,Gnade“ durchforsten, ohne vorauszusetzen, dass der Apostel sich bewusst mit dieser Konzeption auseinandergesetzt hat. Gerade da es sich beim Konzept

156 Barclay, Gift, 358.

157 Barclay, Gift, 358.

158 Barclay, Gift, 360.

159 Barclay, Gift, 361.

160 Barclay, Gift, 362.

161 Dass Barclay, Gift, 362 eine solche Genus-SPECIFICUM-Relation annimmt, ergibt sich aus seiner Formulierung, die Distanz zu Jerusalem und die Einzahl des Besuches ,are cited in support of his contention that he ,did not consult with flesh and blood' (i.e., any human being, $1: 16)$.“ 
des ,Schenkens“ um eine aus anthropologischer Sicht sehr fundamentale Konstante menschlicher Interaktion handelt, ${ }^{162}$ kann Paulus zu dieser Fragestellung natürlich auch Profundes beigetragen haben, ohne explizit diese Absicht vertreten $\mathrm{zu}$ haben. ${ }^{163}$ Aus einer entsprechenden psychologischen Warte könnte man vor dem Hintergrund der von Paulus gemachten einschneidenden Erfahrung die Erzählungen des Apostels als Auseinandersetzungen mit dem in dieser Gotteserfahrung erhaltenen Geschenk verstehen.

Barclay scheint sich diese Option zumindest ansatzweise offen $\mathrm{zu}$ halten, indem er den konstruktiven Charakter seiner Leseweise offen eingesteht. ${ }^{164}$ Zugleich erhebt Barclay jedoch auch den Anspruch, eine (unter anderem) exegetisch robuste und historisch plausible Auslegung des Galaterbriefes zu präsentieren. ${ }^{165}$ Im Hinblick auf das Narrativ in Gal 1,13-17 wird entsprechend nicht nur ein „Ertrag“ zur Gnaden-Thematik erhoben, sondern auch dem Autor selbst eine entsprechende Aussageabsicht zugesprochen. ${ }^{166}$

Es lässt sich also zumindest sagen, dass Barclays Interpretation des Textes an mehreren Punkten mit dessen Struktur kollidiert. Die Makrostruktur des Propositionalgefüges entspricht sicherlich nicht dem, was man erwarten würde, wenn man es mit einer Erzählung zu tun hätte, die den von Barclay postulierten Plot und das von ihm angenommene Thema aufweisen würde. ${ }^{167}$

162 Siehe die Diskussion bei Barclay, Gift, 11-65, der mit der Rolle des Geschenks in der anthropologischen Forschung sein Buch eröffnet.

163 Vgl. Köppe und Kindt, Erzähltheorie, 123 zur Immunität von Figurenanalysen, die sich auf „anthropologische Konstanten“ berufen, gegenüber dem Vorwurf des Anachronismus.

164 Barclay, Gift, 349 verbindet seine eigene Interpretation mit anderen maßgeblichen Lesweisen des Galaterbriefes: „Here are four contrasting readings of Galatians, each with significant insights into the letter, but clearly incompatible in multiple ways. They differ not just in the degrees of emphasis they give to the original context of the letter, but in the ways they read that context, and the connections they draw between it and the contemporary concerns of the interpreter. They integrate the polarities of the letter in very different ways, and even where they agree on its central polarity, they interpret this differently. It is not hard to detext the constructive work of the interpreter as each attempts to correlate the varied themes of the letter; the reading of Galatians that now follows ... is unashamedly also a constructive labor of interpretation. We are forced to ask ourselves again what Galatians is truly about, with specific interest in how the divine gift in Christ structures the theology of the whole.“

165 Barclay, Gift, 350.

166 Eben beispielsweise, wenn Barclay, Gift, 360 (Hervorhebungen nicht im Original) schreibt: „Paul emphasizes God's agency and priority in grace in order to clarify ...“

167 Vgl. unten, Kapitel 16, Abschnitt 4 zur Frage, wie Abweichungen der erwarteten Textgestalt vor dem Hintergrund bestimmter Bedeutungsannahmen die Bewertung dieser semantischen Hypothesen beeinflussen sollte. 
Zugleich weist die Analyse des Propositionalgefüges grundsätzlich natürlich ein gewisses Ungleichgewicht zugunsten textinterner Merkmale auf. ${ }^{168}$ Die tatsächlich vorliegende narrative Vertextung könnte daher unter Umständen durchaus als plausibler Ausdruck der von Barclay angenommenen Handlung herausstellen. Dazu müsste allerdings gezeigt werden, welche Rolle einzelne Lexeme wie $\chi \alpha$ ópı in V. 15 als Leseanweisung spielen. Verweise auf intertextuelle Bezüge (z. B. zu anderen, expliziteren Erörterungen zum Gnaden-Konzept bei Paulus) können dabei ebenso eine Rolle spielen wie die Rekonstruktion des (evtl. besonders „Gnade-relevanten“) Konflikts in Galatien. ${ }^{169}$ Letztlich ist die Plausibilität der von Barclay angenommenen Handlung also auch abhängig davon, wie man seine am Rest des Galaterbriefes und am Römerbrief abgeleitete These der für Paulus so zentralen „inkongruenten Gnade“ bewertet. Freilich dürfte man vom Autor dann auch erwarten dürfen, dass er an der konkreten Stelle Gal 1,13-24 Spannungen zwischen Textstruktur und Textinterpretation wahrnimmt und durch Verweis auf die entsprechenden Hintergründe aufzulösen versucht. Auf jeden Fall als Kritik vorbringen lässt sich also, dass Barclay zumindest an dieser Stelle nicht seinem Maßstab der „exegetischen Robustheit“ gerecht wird.

\subsubsection{Ausblick}

Das hier recht ausführlich diskutierte Beispiel demonstriert, wie stark die Rekonstruktion sinnhafter Verbindungen zwischen temporalen Elementen von an den Text herangetragenen grundsätzlichen „Verstehensweisen“ abhängig ist. Das gewählte Beispiel ist lediglich auf einer tieferen Ebene der Propositionalstruktur ausschließlich chronologisch fokussiert, die temporal geordneten Elemente werden also auf höheren Ebenen durchaus durch nicht-chronologische Konnexionen miteinander in Beziehung gesetzt (anders als bei einer Aneinanderreihung von Sequenz-Blöcken). Trotzdem führen die im Rahmen der Interpretation angenommenen sinnhaften Verbindungen zwischen den erzählten Ereignissen aufgrund unterschiedlicher Vorannahmen über Autor und Situation (und evtl. Bedeutungskonzeption) über diese Makrostruktur hinaus. Der „Witz“ der Erzählung ist eben zu hohem Maße davon abhängig, welche Zielsetzung man hinter

168 Vgl. oben Kapitel 1, Abschnitt 3 zu textinternen und -externen Merkmalen. Heinrich von Siebenthal versucht, z. B. über die Kategorie des „Mitzuverstehenden“ und die Paraphrase der Äußerungsbedeutung die pragmatische Dimension des Textes aufzugreifen (siehe oben, Kapitel 4, Abschnitt 5.3 und 5.4). Die Illokutionsstruktur des Textes bleibt aber hier dennoch unterbelichtet, so lange man nicht auch die nicht-propositionale Verknüpfungungsebene in der Analyse berücksichtigt (siehe oben, Kapitel 4, Abschnitt 5.1 zu in der ,Proposition“ nicht enthaltenen Aspekten und im selben Kapitel Abschnitt 8.2 zu Diskursmarkern).

169 Vgl. Barclay, Gift, 333-337. 
der Narration sieht und wie man die durch die einzelnen Propositionen ausgedrückten Ereignisse vom Autor implizit bewertet und in der erzählten Welt miteinander in Beziehung stehen sieht (bzw. ob man den Autor für die Bestimmung der Bedeutung des Textes überhaupt für relevant ansieht). An Aussagen zu Plot und Thema kommt dieser konstruktive Aspekt der Interpretation besonders deutlich zum Ausdruck.

In noch viel größerem Maße als im hier diskutierten Beispiel tritt das Problem natürlich auf, wenn, wie oben einführend als Problemanzeige angemerkt (Abschnitt 5.2.1), Erzählblöcke auf der äußersten Ebene des Propositionalgefüges durch chronologische Konnexions-Klammern verbunden sind. Wie also die durch mehrmaliges हैं $\varepsilon \iota \tau \alpha$ markierte Sequenz Gal 1,18, 1,21 und 2,1 zu verstehen ist, wie die von Paulus ausgewählten Ereignisse miteinander in Beziehung stehen, ist textgrammatisch zumindest nicht mit Blick auf die propositionale Binnenstruktur der narrativen Vertextung entscheidbar.

Es gibt jedoch andere linguistisch erfassbare Merkmale, welche eine gewisse Basis bieten, um auch in solchen Fällen begründete Annahmen über sinnhafte Verbindungen zwischen konnektoral lediglich temporal geordneten Propositionen und Propositionsgefügen anzustellen. Es handelt sich dabei um Merkmale des Textes, welche durchaus textintern sind, auch wenn sie nicht Teil der propositionalen Binnenstruktur der narrativen Vertextung sind. Der Fokus liegt dabei also zumindest teilweise auf der Einbettung der Erzählung als Teiltext im größeren Textganzen des Briefes. Entsprechend sollen diese Aspekte (das Resultat der Bearbeitung sogenannter „narrationsspezifischer Aufgaben“) weiter unten (Kapitel 8, Abschnitt 5) besprochen werden. 
